\title{
Global modeling of nitrate and ammonium: Interaction of aerosols and tropospheric chemistry
}

\author{
Yan Feng $^{1}$ and Joyce E. Penner ${ }^{1}$ \\ Received 23 June 2005; revised 14 June 2006; accepted 31 August 2006; published 6 January 2007.
}

[1] Global radiative forcing of nitrate and ammonium aerosols has mostly been estimated from aerosol concentrations calculated at thermodynamic equilibrium or using approximate treatments for their uptake by aerosols. In this study, a more accurate hybrid dynamical approach (HDYN) was used to simulate the uptake of nitrate and ammonium by aerosols and the interaction with tropospheric reactive nitrogen chemistry in a threedimensional global aerosol and chemistry model, Umich/IMPACT, which also treats sulfate, sea salt and mineral dust aerosol. The calculated sulfate, ammonium and nitrate aerosol concentrations show good agreement with the available ground-based measurements over both ocean and land areas. The global annual average nitrate aerosol burden is $0.16 \mathrm{Tg} \mathrm{N}$, with $43 \%$ (i.e., $0.079 \mathrm{Tg} \mathrm{N})$ in the fine mode $(\mathrm{D}<1.25 \mu \mathrm{m})$ that scatters most efficiently. The global annual average ammonium burden is $0.29 \mathrm{Tg} \mathrm{N}$ with $92 \%$ in the fine mode. A sensitivity study with a thermodynamic equilibrium model underestimates the fine-mode nitrate aerosol burden by $25 \%$, because of the excessive nitrate formation on coarse aerosols. These underpredictions are especially important in the remote continents or over the oceans, where the availability of the total nitrate is limited. We also examined two common approaches used to treat nitrate and ammonium aerosols in global models, including the first-order gas-to-particle approximation based on uptake coefficients (UPTAKE) and a simple hybrid method that combines the former with an equilibrium model (HYB). The two methods calculate higher nitrate aerosol burdens than HDYN by $+106 \%$ and $+47 \%$, respectively. Both fine- and coarse-model nitrate aerosols are overestimated by UPTAKE, but the overestimation by HYB is mainly due to uptake of nitrate by the coarse aerosols. As a result, HYB calculates lower surface concentrations of the fine-mode nitrate aerosol by up to $50 \%$ over most continental areas, compared to HDYN. Surface $\mathrm{HNO}_{3}$ and $\mathrm{NO}_{\mathrm{x}}$ concentrations are underpredicted by HYB by up to $90 \%$ and $5 \%$, respectively. Since the reaction of $\mathrm{N}_{2} \mathrm{O}_{5}$ on sulfate aerosols is not included in the UPTAKE method, the $\mathrm{NO}_{\mathrm{x}}$ burden and surface concentrations are overestimated by $56 \%$ and a factor of $2-5$, respectively. These results suggest the importance of using the more accurate hybrid dynamical method in the estimates of both aerosol forcing and tropospheric ozone chemistry.

Citation: Feng, Y., and J. E. Penner (2007), Global modeling of nitrate and ammonium: Interaction of aerosols and tropospheric chemistry, J. Geophys. Res., 112, D01304, doi:10.1029/2005JD006404.

\section{Introduction}

[2] Intergovernmental Panel on Climate Change [1994] identified nitrate and ammonium as significant anthropogenic sources of aerosol, but there are only a limited number of global model studies of nitrate and ammonium aerosol concentrations [Adams et al., 1999; Metzger et al., 2002; Liao et al., 2003; Rodriguez and Dabdub, 2004], and their radiative effects [Van Dorland et al., 1997; Adams et al., 2001; Jacobson, 2001; Liao et al., 2004]. Nitrate and ammonium aerosols are highly hygroscopic, and can absorb

\footnotetext{
${ }^{1}$ Department of Atmospheric, Oceanic and Space Sciences, University of Michigan, Ann Arbor, Michigan, USA.

Copyright 2007 by the American Geophysical Union. 0148-0227/07/2005JD006404
}

water to form aqueous solutions under typical atmospheric conditions [Tang and Munkelwitz, 1994; ten Brink et al., 1996]. They may affect aerosol radiative properties by changing the amount of aerosol water uptake at a given relative humidity, as well as by altering the refractive index of aerosols. Both measurements [ten Brink et al., 1996] and model studies [Van Dorland et al., 1997; Adams et al., 2001] have found that nitrate may exert a radiative forcing that is similar to (or even larger than) sulfate aerosols on a regional basis. The relative importance of nitrate versus sulfate aerosol may increase in the future in most industrialized regions of Europe and North America, because of the larger decline of sulfur emissions compared to those of $\mathrm{NO}_{\mathrm{x}}$ in the IPCC A2 scenario for year 2100 [Adams et al., 2001]. Recent studies indicate that the condensation of nitric acid on aerosol particles may enhance aerosol activation to cloud 
droplets by contributing soluble material to the particle surface and elevating the water uptake and growth of aerosol particles [Kulmala et al., 1993, 1995, 1998; Goodman et al., 2000]. Thus full consideration of aerosol composition including hygroscopic components like nitrate and ammonium could be important in the calculation of aerosol indirect forcing.

[3] The formation of nitrate and ammonium aerosol also strongly affects tropospheric chemistry. Nitrate and ammonium aerosols provide additional particle surfaces for scattering incoming ultraviolet solar radiation [Liao et al., 2003] and will thus perturb photochemical oxidant production by altering photolysis frequencies. Moreover, nitrate aerosol is formed through heterogeneous reactions of nitrogen radicals such as $\mathrm{N}_{2} \mathrm{O}_{5}, \mathrm{NO}_{3}$, and $\mathrm{HNO}_{3}$ on aerosol surfaces [Jacob, 2000]. During transport in the atmosphere, $\mathrm{HNO}_{3}$ balances between the gas phase (as nitric acid gas) and the aqueous phase (as nitrate aerosol), determined by its Henry's law coefficient. The formation of nitrate aerosol will affect the rate of conversion of $\mathrm{N}_{2} \mathrm{O}_{5}$ to $\mathrm{HNO}_{3}(\mathrm{~g})$. For example, Riemer et al. [2003] found that aerosol nitrate lowers the reaction probability of the $\mathrm{N}_{2} \mathrm{O}_{5}$ conversion to $\mathrm{HNO}_{3}(\mathrm{~g})$ by one order of magnitude. Since this conversion was estimated to decrease tropospheric ozone concentrations by $8-25 \%$ during the winter and $6-10 \%$ during the summer [Dentener and Crutzen, 1993; Dentener et al., 1996; Tie et al., 2003], it is important to account for the presence of nitrate aerosol in computing this rate. The more recent study by Bauer et al. [2004] found a global annual mean decrease in tropospheric ozone concentration of $5 \%$ with most of the ozone reduction attributed to the uptake of $\mathrm{HNO}_{3}$ by aerosols. During these heterogeneous processes, ammonium helps to retain nitrate in the aerosol phase by neutralizing the aerosol acidity [Adams et al., 1999].

[4] In order to study the effects of nitrate and ammonium aerosol on radiative processes and gas-phase chemistry, one must first consider the partitioning of semivolatile nitrate and ammonium between the gas and aerosol phases. Many thermodynamic equilibrium models have been developed over the past 20 years for this purpose. However, assuming thermodynamic equilibrium between the gas and aerosol phases may not be appropriate for coarse aerosols in global models. Meng and Seinfeld [1996] and Seinfeld and Pandis [1998] have shown that at low temperatures and low aerosol concentrations, equilibrium on coarse aerosol particles is only slowly established, with a timescale of the order of several hours or even days. This is longer than the time step normally used in chemical transport models (about 1 hour). Departure from the gas-aerosol equilibrium state has also been observed for coarse aerosols in field studies (e.g., the SCAQS study [John et al., 1989]). Different approximations have been developed to treat nitrate and ammonium in aerosols since accurately solving the dynamic mass transfer equations over the entire aerosol size range is computationally expensive. One approach is to add a mass transport constraint to the equilibrium calculations. In this method, one first calculates the equilibrium concentrations for the gas and bulk-aerosol phases, and then distributes the calculated total aerosol concentrations to different size sections according to a weighting function derived from the mass transfer equation [Pandis et al., 1993]. This method has been applied to describe the distribution of volatile aerosol components in air quality models [Pandis et al., 1993; Lurmann et al., 1997], and Rodriguez and Dabdub [2004] implemented it in a global chemical transport model (IMAGES) to study nitrate and ammonium aerosols. However, this method still assumes that equilibrium is established at the beginning of each time step. It also neglects the differences in the chemical driving force of each size section on the condensation of volatile species, since it considers aerosols with different size distributions such as sulfate, sea salt and mineral dust, in a bulk aerosol model. Another treatment for nitrate and ammonium in aerosol was developed and used by Liao et al. [2003]. They assumed thermodynamic equilibrium for nitrate and ammonium on sulfate aerosol, and considered the first-order uptake of nitrate by dust aerosol, using an uptake (or reaction) coefficient for $\mathrm{HNO}_{3}$ [Dentener and Crutzen, 1993].

[5] In the present study, we calculate the global concentration of nitrate and ammonium aerosol using a more accurate hybrid dynamical approach [Capaldo et al., 2000]. Nitrate and ammonium on submicron aerosols $(\mathrm{D}<1.25 \mu \mathrm{m})$ are computed with a gas-aerosol thermodynamic equilibrium model [Jacobson, 1999]; for coarse aerosols $(\mathrm{D}>1.25 \mu \mathrm{m})$, the uptake of nitrate and ammonium aerosols is determined by dynamical mass transfer calculations.

[6] The following section describes the three-dimensional global aerosol and chemistry transport model used in this study, and new enhancements to the global model including a simple tropospheric nitrogen chemistry scheme, a global ammonia cycle and the interaction between gases and aerosols. Section 3 presents the global distribution of the calculated nitrate and ammonium aerosol concentrations, a comparison with the available ground-based measurements, and the global aerosol budgets. This is followed in section 4 by a sensitivity study with a thermodynamic equilibrium model. Section 5 compares the global budgets with other model studies, and examines the differences in the calculated gaseous and aerosol concentrations between our nitrate treatment and two methods used in other studies. The final section summarizes the major conclusions of this study.

\section{Model Description}

\subsection{Global Aerosol and Chemistry Transport Model}

[7] A global aerosol and chemistry transport model, the University of Michigan (Umich) version of the Lawrence Livermore National Laboratory (LLNL) IMPACT model [Liu and Penner, 2002; Feng et al., 2004; Rotman et al., 2004; Liu et al., 2005], was used as the framework for this study. The spatial resolution of the IMPACT model is $2^{\circ}$ latitude by $2.5^{\circ}$ longitude in the horizontal, with 26 layers in the vertical from the surface to $0.1 \mathrm{hPa}$ (the mean pressure levels are 994, 971, 930, 875, 813, 745, 675, $605,537,472,410,353,302,258,220,187,158,133$, $112,94.1,79.3,67.0,56.7,37.7,14.3$, and $2.64 \mathrm{hPa}$ ). For this study, the transport model was driven by assimilated meteorological fields for year 1997, which were available at a 6-hour time interval from the NASA Goddard Data Assimilation Office (DAO) general circulation model (GCM) and were interpolated to a 1-hour time interval, which was the model time step for tracer advection. 
[8] The IMPACT model uses a flux-form semi-Lagrangian advection scheme [Lin and Rood, 1996]. Dry deposition rates for gases are calculated using a package developed at Harvard University on the basis of the work of Jacob and Wofsy [1990], Wesely [1989], and Walcek et al. [1986]. Dry deposition of aerosol particles uses a resistance-in-series parameterization following Zhang et al. [2001]. The wet deposition scavenging parameterization is based on the Harvard wet scavenging model [Mari et al., 2000; Liu et al., 2001] that is enhanced over previous models [Giorgi and Chameides, 1986; Balkanski et al., 1993]. In convective updrafts, the fraction of tracer scavenged is calculated on the basis of the rate constant for conversion of cloud condensate (including liquid and ice) to precipitation (assumed to be $0.005 \mathrm{~s}^{-1}$ ) and the fraction of tracer present in the cloud condensate $f_{i}$ (scavenging efficiency). The scavenging efficiency of gases depends on their Henry's law coefficients, except for highly soluble $\mathrm{HNO}_{3}$ which is assumed to be completely removed. The scavenging efficiencies of sulfate, nitrate, ammonium, and carbonaceous aerosol are 1.0, 1.0, 1.0, and 0.4 in the IMPACT model, respectively. In addition, a first-order rainout (in-cloud scavenging of aerosols or gases by cloud or precipitation) and washout (below-cloud scavenging of aerosols or gases by cloud or precipitation) parameterization is applied for both convective and large-scale precipitation. The fraction of a tracer lost because of rainout depends on the wet scavenging efficiency of the tracer, the horizontal areafraction of the grid box experiencing precipitation, and conversion rate of cloud condensate to precipitation. Washout by large-scale precipitation is computed as a first-order loss process using a rate which is calculated by multiplying a constant scavenging efficiency, $0.1 \mathrm{~mm}^{-1}$, by the precipitation rate (in $\mathrm{mm} \mathrm{hr}^{-1}$ ) in the precipitating fraction of the grid box [Balkanski et al., 1993]. Resuspension is calculated in any grid box where there is net evaporation of precipitation. A fraction (assumed to be half) of or the entire tracer precipitating from above is released in the grid box to reflect the partial or total evaporation of precipitation, respectively. Cumulus transport in the IMPACT model was derived from the relaxed Arakawa-Schubert scheme, as described in detail by Penner et al. [1998]. The cumulus mass flux and convective cloud detrainment used in the scheme are derived from the DAO meteorological fields. A full description of the transport and deposition schemes is given in Rotman et al. [2004] for the original IMPACT model.

[9] An online sulfur model that predicts the concentrations of $\mathrm{SO}_{2}, \mathrm{SO}_{4}^{2-}$ (represented in 3 aerosol size bins or sections: $<0.05 \mu \mathrm{m}, 0.05-0.63 \mu \mathrm{m}, 0.63-1.25 \mu \mathrm{m}$ in radius), $\mathrm{H}_{2} \mathrm{O}_{2}$ and DMS was developed for the Umich version of the IMPACT model [Liu and Penner, 2002; Liu et al., 2005]. This model includes the Global Emissions Inventory Activity (GEIA) emissions of $\mathrm{SO}_{2}$ and $\mathrm{SO}_{4}^{2-}$ from fossil fuel combustion and industrial activities, $\mathrm{SO}_{2}$ emissions from biomass burning, aircraft, and noneruptive volcanoes, as well as an oceanic DMS source. $\mathrm{SO}_{2}$ is oxidized to $\mathrm{SO}_{4}^{2-}$ in cloud by dissolved $\mathrm{O}_{3}$ and $\mathrm{H}_{2} \mathrm{O}_{2}$, and in the gas phase by the $\mathrm{OH}$ radical. Both $\mathrm{OH}$ and $\mathrm{NO}_{3}$ radicals oxidize DMS and generate $\mathrm{SO}_{4}^{2-} \cdot \mathrm{H}_{2} \mathrm{O}_{2}$ is included as a prognostic species, formed from two $\mathrm{HO}_{2}$ molecules. Three-dimensional monthly average $\mathrm{O}_{3}, \mathrm{OH}$, and $\mathrm{HO}_{2}$ concentration fields are taken from a 1-year simulation of the chemical transport model GRANTOUR using the climate model CCM1 meteorological fields [Penner et al., 1994]. The diurnal cycle of $\mathrm{OH}$ and $\mathrm{HO}_{2}$ is approximated using the cosine of the solar zenith angle. $\mathrm{NO}_{3}$ is calculated interactively by a nitrogen chemistry model to be described next.

[10] Feedbacks between the processes we include in the model and the fixed concentrations used to simulate the sulfur cycle (i.e., $\mathrm{O}_{3}, \mathrm{OH}$, and $\mathrm{HO}_{2}$ ) are possible. For example, the aqueous reaction of $\mathrm{H}_{2} \mathrm{O}_{2}$ with $\mathrm{SO}_{2}$ could decrease $\mathrm{OH}$ and $\mathrm{HO}_{2}$ concentrations and the aqueous reaction of $\mathrm{O}_{3}$ with $\mathrm{SO}_{2}$ could decrease $\mathrm{O}_{3}$. As we show below, there is also a feedback between $\mathrm{NO}_{\mathrm{x}}$ concentrations and the amount of nitrate in aerosols. The feedbacks between the formation of sulfate aerosol and $\mathrm{O}_{3}, \mathrm{OH}$ and $\mathrm{HO}_{2}$ are relatively small, because the loss rates due to these aqueous phase processes are small compared to the formation rates from gas phase chemistry. As discussed below, the feedbacks between the formation of nitrate in aerosol and $\mathrm{NO}_{\mathrm{x}}$ can be large, depending on the method used to calculate nitrate in aerosol. This change in $\mathrm{NO}_{\mathrm{x}}$ would also ultimately affect $\mathrm{O}_{3}$ concentrations, but an evaluation of this feedback is beyond the scope of the present paper.

[11] The wet size used in the dry deposition scheme is calculated by the empirical expression of Gerber [1985],

$$
R_{w}=\left(\frac{C_{1} R_{d}^{C_{2}}}{C_{3} R_{d}^{C_{4}}-\log S}+R_{d}^{3}\right)^{\frac{1}{3}}
$$

where $R_{w}$ and $R_{d}$ are the wet and dry particle radius, $S$ is the relative humidity expressed as a fraction, and $C_{1}, C_{2}, C_{3}$, and $C_{4}$ are constants whose values are $0.4809,3.082$, $3.110 \times 10^{-11}$, and -1.428 , respectively. The model yields an annual average sulfate burden of $0.80 \mathrm{Tg} \mathrm{S}$. This value is intermediate in comparison with other sulfur models that give burdens ranging from $0.53 \mathrm{Tg} \mathrm{S}$ [Chin et al., 1996] to $1.05 \mathrm{Tg} \mathrm{S}$ [Lelieveld et al., 1997].

[12] Sea salt emissions in the IMPACT model were provided by Gong et al. [1997]. An interpolation was made on the basis of the algorithm of Monahan et al. [1986] to derive the size-segregated mass fluxes. Following emission, the sea salt mass is carried in 4 aerosol size bins $(0.05-$ $0.63 \mu \mathrm{m}, 0.63-1.25 \mu \mathrm{m}, 1.25-2.5 \mu \mathrm{m}, 2.5-10 . \mu \mathrm{m}$ in radius). The constants $C_{1}, C_{2}, C_{3}$, and $C_{4}$ in the equation (1) which account for the relative humidity dependence of sea salt are $0.7674,3.079,2.573 \times 10^{-11}$, and -1.424 , respectively. The model predicted sea salt burden is about $3.13 \mathrm{Tg}$.

[13] The dust emission fluxes calculated by Ginoux et al. [2001] were interpolated and represented in the same 4 size bins as the sea salt aerosol [Liu et al., 2005]. Although dust particles may acquire a soluble coating and absorb water, their dry sizes are used in the calculation of the dry deposition velocity since the extent of their water uptake is not well established. For in-cloud scavenging of dust particles, we followed the assumption of Ginoux et al. [2001] and completely scavenged dust particles within both convective and large-scale clouds. The model calculated dust burden is about 23.21 Tg. Model estimates of dust burden range from 13.8 Tg by Takemura et al. [2000] to 18.7 $\mathrm{Tg}$ by Tegen et al. [2002], and to $31-40 \mathrm{Tg}$ by Ginoux et al. [2001]. The large differences between these studies 
Table 1. Tropospheric Gas-Phase Reactions and Heterogeneous Reactions Included in the Model

\begin{tabular}{|c|c|}
\hline & Chemical Reactions \\
\hline $\begin{array}{l}\text { (R1) } \\
\text { (R2) } \\
\text { (R3) }\end{array}$ & $\begin{array}{l}\quad \text { Day-time Scheme }[\text { Kraus et al., 1996] } \\
\mathrm{NO}_{2}+\mathrm{OH}+\mathrm{M} \rightarrow \mathrm{HNO}_{3}+\mathrm{M} \\
\mathrm{HNO}_{3}+\mathrm{h} \nu \rightarrow \mathrm{NO}_{2}+\mathrm{OH} \\
\mathrm{HNO}_{3}+\mathrm{OH} \rightarrow \mathrm{NO}_{3}+\mathrm{H}_{2} \mathrm{O}\end{array}$ \\
\hline $\begin{array}{l}\text { (R4) } \\
\text { (R5) }\end{array}$ & $\begin{array}{l}\text { Nighttime Scheme } \\
\mathrm{NO}_{2}+\mathrm{O}_{3} \rightarrow \underset{M}{\mathrm{NO}_{3}+\mathrm{O}_{2}} \\
\mathrm{NO}_{2}+\mathrm{NO}_{3} \stackrel{M}{\longleftrightarrow} \mathrm{N}_{2} \mathrm{O}_{5}\end{array}$ \\
\hline $\begin{array}{l}\text { (R6) } \\
\text { (R7) } \\
\text { (R8) } \\
\text { (R9) } \\
\text { (R10) } \\
\text { (R11) } \\
\text { (R12) } \\
\text { (R13) }\end{array}$ & $\begin{array}{l}\quad \text { Heterogeneous Interaction } \\
\mathrm{N}_{2} \mathrm{O}_{5}+\mathrm{H}_{2} \mathrm{O}(\mathrm{a}) \rightarrow 2 \mathrm{HNO}_{3} \\
\mathrm{NH}_{3}+\mathrm{H}_{2} \mathrm{SO}_{4}(\mathrm{a})=\left(\mathrm{NH}_{4}\right)_{2} \mathrm{SO}_{4} \text { or } \mathrm{NH}_{4} \mathrm{HSO}_{4} \text { or }\left(\mathrm{NH}_{4}\right)_{3} \mathrm{H}\left(\mathrm{SO}_{4}\right)_{2} \\
\mathrm{HNO}_{3}+\mathrm{NH}_{3}=\mathrm{NH}_{4} \mathrm{NO}_{3} \\
\mathrm{HNO}_{3}+\mathrm{NaCl}(\mathrm{a})=\mathrm{NaNO}_{3}+\mathrm{HCl} \\
2 \mathrm{HNO}_{3}(\mathrm{~g})+\mathrm{CaCO} \mathrm{CaO}_{3}=\mathrm{Ca}\left(\mathrm{NO}_{3}\right)_{2}+\mathrm{H}_{2} \mathrm{O}+\mathrm{CO}_{2} \\
2 \mathrm{HNO}_{3}(\mathrm{~g})+\mathrm{MgCO}_{3}=\mathrm{Mg}\left(\mathrm{NO}_{3}\right)_{2}+\mathrm{H}_{2} \mathrm{O}+\mathrm{CO}_{2} \\
2 \mathrm{HNO}_{3}(\mathrm{~g})+\mathrm{Na}_{2} \mathrm{CO}_{3}=2 \mathrm{NaNO}_{3}+\mathrm{H}_{2} \mathrm{O}+\mathrm{CO}_{2} \\
2 \mathrm{HNO}_{3}(\mathrm{~g})+\mathrm{K}_{2} \mathrm{CO}_{3}=2 \mathrm{KNO}_{3}+\mathrm{H}_{2} \mathrm{O}+\mathrm{CO}_{2} \\
\end{array}$ \\
\hline
\end{tabular}

result from large uncertainties in emissions and the different wet and dry deposition schemes used in the models.

[14] A longer description of the aerosol module in the Umich/IMPACT model and a comparison of the model predicted aerosol concentrations and optical depths with the available observations are given by Liu et al. [2005].

\subsection{Nitrogen Chemistry}

[15] The gas-phase precursors of nitrate, $\mathrm{HNO}_{3}$ and $\mathrm{N}_{2} \mathrm{O}_{5}$, are calculated online in the model with a simple nitrogen chemistry mechanism. The scheme allows 5 tracers to be transported: $\mathrm{NO}_{\mathrm{x}}\left(\mathrm{NO}+\mathrm{NO}_{2}\right), \mathrm{NO}_{3}, \mathrm{~N}_{2} \mathrm{O}_{5}$, and $\mathrm{HNO}_{3}$. Table 1 lists the tropospheric chemical reactions included in the model. The $\mathrm{NO}_{2}$ concentrations are derived by assuming that photochemical equilibrium is reached between $\mathrm{NO}$ and $\mathrm{NO}_{2}$. Since the reactivity of $\mathrm{NO}_{3}$ on aerosol surfaces is much smaller than that of $\mathrm{N}_{2} \mathrm{O}_{5}$ and $\mathrm{HNO}_{3}$, heterogeneous hydrolysis of $\mathrm{NO}_{3}$ is neglected in this study. The chemistry of gas phase nitrogen in the stratosphere is treated more simply. Its sole function is to provide the proper partitioning between $\mathrm{NO}_{\mathrm{x}}$ and $\mathrm{NO}_{\mathrm{y}}=\mathrm{HNO}_{3}+$ $\mathrm{NO}_{\mathrm{x}}$ for the input of $\mathrm{NO}_{\mathrm{y}}$ at the tropopause. Following Kraus et al. [1996], $\mathrm{NO}_{\mathrm{x}}$ is converted to $\mathrm{HNO}_{3}$ everywhere above the tropopause with an e-folding time constant of 13 days. $\mathrm{HNO}_{3}$ is converted back to $\mathrm{NO}_{2}$ by photolysis, at varying frequencies up to $3 \times 10^{-7}$.

[16] The global fields of $\mathrm{OH}$ and $\mathrm{O}_{3}$ are prescribed as monthly averages as described above. Photolysis frequencies were computed interactively every hour from a look-up table [Feng et al., 2004] that accounts for absorption by $\mathrm{O}_{2}$ and $\mathrm{O}_{3}$, Rayleigh scattering, and Mie scattering by clouds and aerosols. Five $\mathrm{NO}_{\mathrm{x}}$ sources (emitted as $\mathrm{NO}_{2}$ ) were included in this study following Rotman et al. [2004]: $21.5 \mathrm{Tg} \mathrm{N}$ per year from industrial activities/fossil fuel combustion, $6.4 \mathrm{Tg} \mathrm{N}$ per year from biomass burning, 5.0 Tg $\mathrm{N}$ per year from lightning, 5.5 Tg $\mathrm{N}$ per year from soil processes, and $0.5 \mathrm{Tg} \mathrm{N}$ per year from aircraft emissions. Initial stratospheric $\mathrm{HNO}_{3}$ concentrations were specified, on the basis of model results from a full chemistry version of the Umich/IMPACT model [Ito et al., 2004].
[17] The main limitation of this simplified nitrogen chemistry is that it omits organic nitrates. Since organic nitrates form in source regions and transport $\mathrm{NO}_{\mathrm{x}}$ to the remote troposphere, this omission may result in overpredicted $\mathrm{NO}_{\mathrm{x}}$ and $\mathrm{HNO}_{3}$ concentrations in source regions and underpredicted $\mathrm{NO}_{\mathrm{x}}$ and $\mathrm{HNO}_{3}$ concentrations in the remote troposphere [e.g., Singh et al., 1998, 2000; Schultz et al., 1999].

[18] For nitric acid, the effective Henry's law constant used in the dry deposition scheme is $3.17 \times 10^{11} \mathrm{M} \mathrm{atm}^{-1}$ at $\mathrm{pH}=5$. The size-dependent dry deposition of nitrate aerosol used the effective radius for the dominant aerosol type in each size section. Thus the dry deposition of nitrate in the size section, $\mathrm{r}: 0.01-0.63 \mu \mathrm{m}$ (bin 1) was treated the same as sulfate, while that in the size range from 0.63 to $2.5 \mu \mathrm{m}$ (bins 2 and 3) was treated the same as sea salt, and that in the range $2.5-10 \mu \mathrm{m}$ (bin 4), was treated the same as dust aerosol. The wet scavenging efficiency for nitrate aerosol was set to 1.0 , the same as that for sulfate aerosol.

\subsection{Ammonia Cycle}

[19] The ammonia cycle was simulated by adding two tracers: ammonium $\left(\mathrm{NH}_{4}^{+}\right)$and its gas-phase precursor ammonia $\left(\mathrm{NH}_{3}\right)$ to the IMPACT model. Ammonia emissions were taken from the global inventory of Bouwman et al. [1997]. The total ammonia source included in this inventory is estimated to be $54 \mathrm{Tg} \mathrm{N}$ per year, and Table 2 lists the contributions from individual sources. The fact that fertilizer related activities contribute most to the ammonia emissions implies that agricultural regions tend to have the highest ammonia emissions. The total emissions estimate of this inventory is higher than the $45 \mathrm{Tg} \mathrm{N}$ per year used by Dentener and Crutzen [1994] in their model of the ammonia cycle, lower than the $75 \mathrm{Tg} \mathrm{N}$ per year estimate of Schlesinger and Hartley [1992], and almost the same as the 54 Tg N per year estimate of Warneck [1988]. Although some sources, for example, those from crops, fertilizer, and animal waste, should vary seasonally depending on the crop production cycle and temperature, their monthly variations are not available in the current ammonia inventory. Thus, in the absence of more detailed information, only the annual average emission fluxes from all the sources were used in this study.

[20] Ammonia $\left(\mathrm{NH}_{3}\right)$ undergoes one reaction in the atmosphere with the $\mathrm{OH}$ radical [DeMore et al., 1997],

$$
\mathrm{NH}_{3}+\mathrm{OH} \rightarrow \mathrm{NH}_{2}+\mathrm{H}_{2} \mathrm{O}
$$

Table 2. Global Ammonia Emission by Source [Bouwman et al., 1997]

\begin{tabular}{lc}
\hline \multicolumn{1}{c}{ Source } & Emission, $\mathrm{Tg} \mathrm{N}$ per year \\
\hline Domesticated animals & 21.6 \\
Fertilizers & 9.0 \\
Oceans & 8.2 \\
Biomass burning & 5.9 \\
Crops & 3.6 \\
Humans & 2.6 \\
Soils under natural vegetation & 2.4 \\
Other & 0.4 \\
Total & 53.6 \\
\hline
\end{tabular}


We did not include this reaction in this study, since it only plays an insignificant role in the global ammonia budget [Adams et al., 1999]. For wet deposition of $\mathrm{NH}_{3}$, we use an effective Henry's law coefficient of $1.05 \times 10^{6} \mathrm{M}$ atm $^{-1}$ at $\mathrm{pH}=5$. Aerosol ammonium was treated similarly to nitrate aerosol in the dry and wet deposition schemes.

\subsection{Heterogeneous Interaction of Aerosols and Gas-Phase Chemistry}

[21] Aerosol particles are frequently found as internal mixtures with multiple components including sulfate, sea salt, nitrate and dust compounds [Okada et al., 1990; Fan et al., 1996; Zhou et al., 1996; Niimura et al., 1998; Yamato and Tanaka, 1994; Zhang et al., 2003], probably as a result of condensation and coagulation processes. Therefore sulfate, sea salt and mineral dust aerosols were assumed to be internally mixed in aerosol thermodynamics. Organic aerosol compounds may contribute to a large fraction of total aerosol mass; however, little is known about their composition and hygroscopic properties. Although a range of water-soluble organic compounds have been identified in the atmosphere [Saxena and Hildemann, 1996], a better characterization of the organic components of the aerosol is needed in order to characterize their water uptake and interaction with other compounds. Therefore we did not consider the formation of nitrate and ammonium on organic aerosols. Similarly, the uptake of nitrate and ammonium on black carbon was not considered, since black carbon is unlikely to be hydrated except in association with organics and other compounds.

[22] The chemical composition of sea salt aerosol is assumed to be $100 \%$ of $\mathrm{NaCl}$. Dust aerosols generally consist of insoluble metal oxides and a small fraction of alkaline components. The alkalinity of dust is to a great extent determined by the calcium carbonate $\left(\mathrm{CaCO}_{3}\right)$ content. This varies with the source region of the dust aerosol and may be modified by other pollutants during longdistance transport. In this study, mineral dust aerosol is assumed to be: $7 \% \mathrm{CaCO}_{3}, 5.5 \% \mathrm{MgCO}_{3}, 3.3 \% \mathrm{~K}_{2} \mathrm{CO}_{3}$, $2.6 \% \mathrm{Na}_{2} \mathrm{CO}_{3}, 60 \% \mathrm{SiO}_{2}, 14.1 \% \mathrm{Al}_{2} \mathrm{O}_{3}$ and $6.9 \% \mathrm{Fe}_{2} \mathrm{O}_{3}$ [Gillette et al., 1993]. This gives an average of $\mathrm{Ca}^{2+}$ content of $4.2 \%$, which is somewhat larger than the global average crustal Ca content of $3.6 \%$ given by Jaenicke [1988], but smaller than the value of $5 \%$ used in most previous model studies [Dentener et al., 1996; Liao et al., 2003]. In addition, whereas most previous studies considered only $\mathrm{Ca}^{2+}$ for the alkaline material in dust aerosol, we have explicitly included the effects of $\mathrm{Mg}^{2+}, \mathrm{K}^{+}$, and $\mathrm{Na}^{+}$. The heterogeneous reactions included in the model are also shown in Table 1.

[23] The heterogeneous uptake of nitrate and ammonium by aerosol mixtures is simulated in the Umich/IMPACT model using a hybrid dynamical approach (HDYN). With this method, a thermodynamic equilibrium model [Jacobson, 1999] is applied to aerosols in size bin 1 (D < $1.25 \mu \mathrm{m}$, hereafter referred to as the fine mode), while the gas and aerosol concentrations are determined by dynamically solving the mass transfer equations for particles in the other 3 bins ( $\mathrm{D}>1.25 \mu \mathrm{m}$, hereafter referred to as the coarse mode). Capaldo et al. [2000] applied a similar approach in an air pollution model, and they found that this method maintained most of the predictive capability of dynamically solving mass transfer equations over the entire aerosol size range, and was 50 times more computationally efficient in their test cases. Following Capaldo et al. [2000], we selected the same critical size (below which equilibrium is assumed and above which the mass transport is calculated) at a diameter equal to $1.25 \mu \mathrm{m}$. Wexler and Seinfeld [1990] and Dassios and Pandis [1999] calculated the equilibrium time constants for ammonium nitrate aerosol and indicated that particles with diameter less than $1 \mu \mathrm{m}$ generally have equilibrium timescales of the order of a few minutes under typical atmospheric conditions. Since our transport model time step is one hour and the equilibrium timescale depends mostly on particle size, the equilibrium assumption is well justified for aerosols in the fine mode. This assures that results are similar to fully dynamical calculations. While Capaldo et al. [2000] performed equilibrium calculations every $1 \mathrm{~min}$, we only do so at the beginning of each model step. We tested this assumption, and under most conditions, there was less than a $7 \%$ percent difference compared to a calculation that adjusted concentrations to equilibrium every minute. Even smaller errors occur when conditions are near equilibrium. This is because the diffusion of gases to the coarse particles is slow and usually has little impact on finemode equilibrium processes over a 1-hour time step. The operator-splitting method used in the global model eliminates any effects from other processes during the model time step. Aerosol chemical composition is usually uniform over the submicron size range: continental aerosols are mainly composed of sulfate, ammonium, and nitrate; marine aerosols are mainly composed of sea salt. Therefore the chemical driving force among particles in the fine mode is similar and there is no need to use a finer division of size bins for the equilibrium calculation. However, since only one bin out of 4 bins is assumed to be in equilibrium in our calculation compared to 6 bins out of 10 bins in the work by Capaldo et al. [2000], we only obtain a factor of 3 or 4 speed up compared to a full dynamical calculation over all bins in this study.

[24] The partitioning of nitrate and ammonium in the coarse mode is described by the mass transfer equations,

$$
\left\{\begin{array}{l}
\frac{d C_{\infty}}{d t}=-\sum_{i}^{n} k_{i}\left(C_{\infty}-C_{i, e q}\right) \\
\frac{d C_{i}}{d t}=k_{i}\left(C_{\infty}-C_{i, e q}\right) \\
k_{i}=4 \pi D_{g} r_{i} n_{i} \frac{0.75 \alpha\left(1+K n_{i}\right)}{K n_{i}^{2}+K n_{i}+0.283 K n_{i} \alpha+0.75 \alpha} .
\end{array}\right.
$$

where $D_{g}$ is the diffusivity, $r_{i}$ is the radius of particles in size bin $i, n_{i}$ is the aerosol number concentration, $C_{\infty}$ is the ambient gas-phase concentration (moles per $\mathrm{m}^{3}$ of air) and $C_{i}$ is the aqueous-phase concentration. $C_{i, e q}$ is the equilibrium vapor concentration on the particle surface, which is calculated with the thermodynamic equilibrium model based on the aerosol composition of each size bin. The formulation of the mass transfer coefficient $k_{i}$ is based on the solution of Fuchs and Sutugin [1971], where $K n_{i}$ is the Knudsen number, and the accommodation coefficient $(\alpha)$ represents the sticking probability of a vapor molecule at the surface of a particle. We used $0.193,0.092$, and 0.1 for the accommodation coefficients of $\mathrm{HNO}_{3}, \mathrm{NH}_{3}$, and 


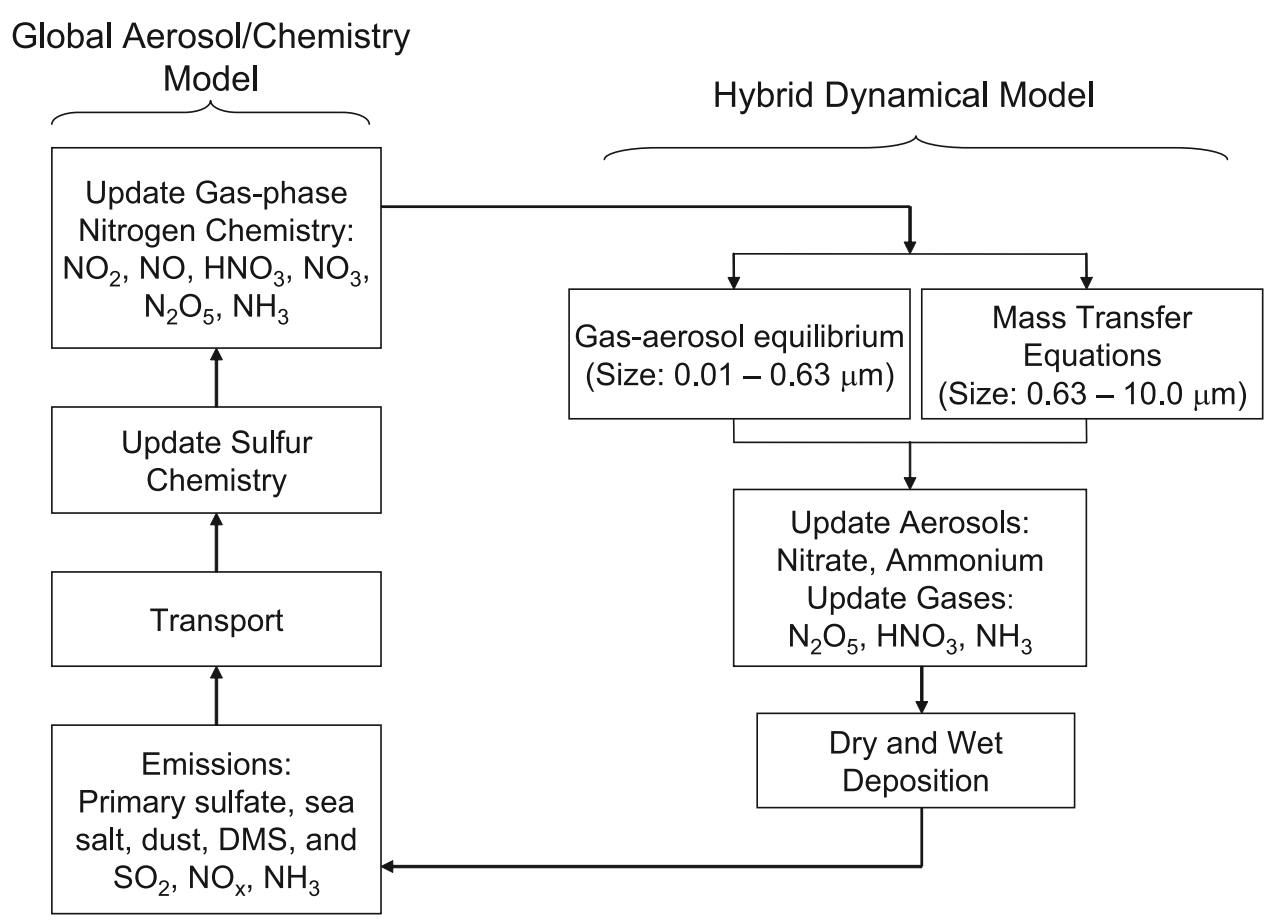

Figure 1. Schematic diagram of the integration of the hybrid dynamical (HDYN) method in the global chemistry and aerosol transport model (Umich/IMPACT).

$\mathrm{N}_{2} \mathrm{O}_{5}$ on aerosols, respectively, on the basis of measurements at $298 \mathrm{~K}$ by Van Doren et al. [1990, 1991]. These values for $\alpha$ are at the upper end of the corresponding uptake coefficients $(\gamma)$ used in the literature, satisfying the general relationship $\gamma \leq \alpha$. Equations (3) were integrated over the model time step (1 hour) and were solved simultaneously for aerosol nitrate $\left(\mathrm{NO}_{3}^{-}\right)$and aerosol ammonium $\left(\mathrm{NH}_{4}^{+}\right)$concentrations in each of the 3 aerosol bins of the coarse mode as well as for $\mathrm{HNO}_{3}(\mathrm{~g})$ and $\mathrm{NH}_{3}(\mathrm{~g})$.

[25] This hybrid dynamical method should be more accurate than thermodynamic equilibrium models. HDYN considers the diffusion constraint in the mass transport from gas phase to particles, which frequently causes coarse aerosols to be in a nonequilibrium state. This method is also better than the first-order removal approximation in which the removal rate $K$ is usually defined as [Schwartz, 1986],

$$
K=\left(\frac{r}{D_{g}}+\frac{4}{v \gamma}\right)^{-1} A
$$

where $r$ is the aerosol radius, $A$ is the aerosol surface area, $D_{g}\left(\mathrm{~cm}^{2} \mathrm{~s}^{-1}\right)$ is the gas phase diffusion coefficient, and $v$ is the mean molecular speed $\left(\mathrm{cm} \mathrm{s}^{-1}\right) . \gamma$ is the uptake coefficient, which is the ratio of the number of gaseous molecules entering the particle over the number of molecules colliding with the surface. Compared to the mass transfer equation (equation (3)), equation (4) does not explicitly include the equilibrium vapor concentration of species on particle surfaces $\left(C_{i, e q}\right)$, which depends on the ambient relative humidity, temperature, and the immediate aerosol chemical composition during gas-to-aerosol diffusion. Instead, the dependence of the mass transfer rate on
$C_{i, e q}$ is approximately represented by uptake coefficients measured under certain laboratory conditions. The use of different uptake coefficients can significantly affect the results of global model studies. For example, Bauer et al. [2004] found that with the upper limit for $\gamma_{N 2 O 5}(0.02)$, tropospheric ozone mass is decreased by $0.8 \%$, while with the lower limit of $\gamma_{N 2 O 5}(0.003)$, the reaction had almost no impact on ozone concentrations. They also found that lowering the uptake coefficient of $\mathrm{HNO}_{3}$ by two orders of magnitude from 0.1 to 0.001 resulted in a much smaller decrease of tropospheric ozone (from $4.5 \%$ to $2.2 \%$ ).

[26] Figure 1 shows a schematic of the integration of the hybrid dynamical approach into the global aerosol and chemistry transport model, Umich/IMPACT. The integrated model was run for a period of four simulation months: January, April, July and October, to obtain a representation of the annual average of the global concentrations of nitrate and ammonium aerosol. Unless otherwise specified, global and annual aerosol budgets were estimated from these 4-month simulations. A 2-month spin-up time was used to generate background values as initial concentrations for production runs. The global model requires 3 days of the CPU time on 64 IBM SP3 processors (each processor has a peak performance of 1.5 GFlops) to complete a 1-month simulation.

\section{Global Results}

\subsection{Nitrate Aerosol}

[27] The simulated monthly averaged concentrations of the fine- and coarse-mode nitrate aerosol near the surface (i.e., in the lowest three layers of the model) are shown in Figure 2 for January and July. Nitrate aerosol concentrations are expressed in their equivalent gaseous volume mixing 

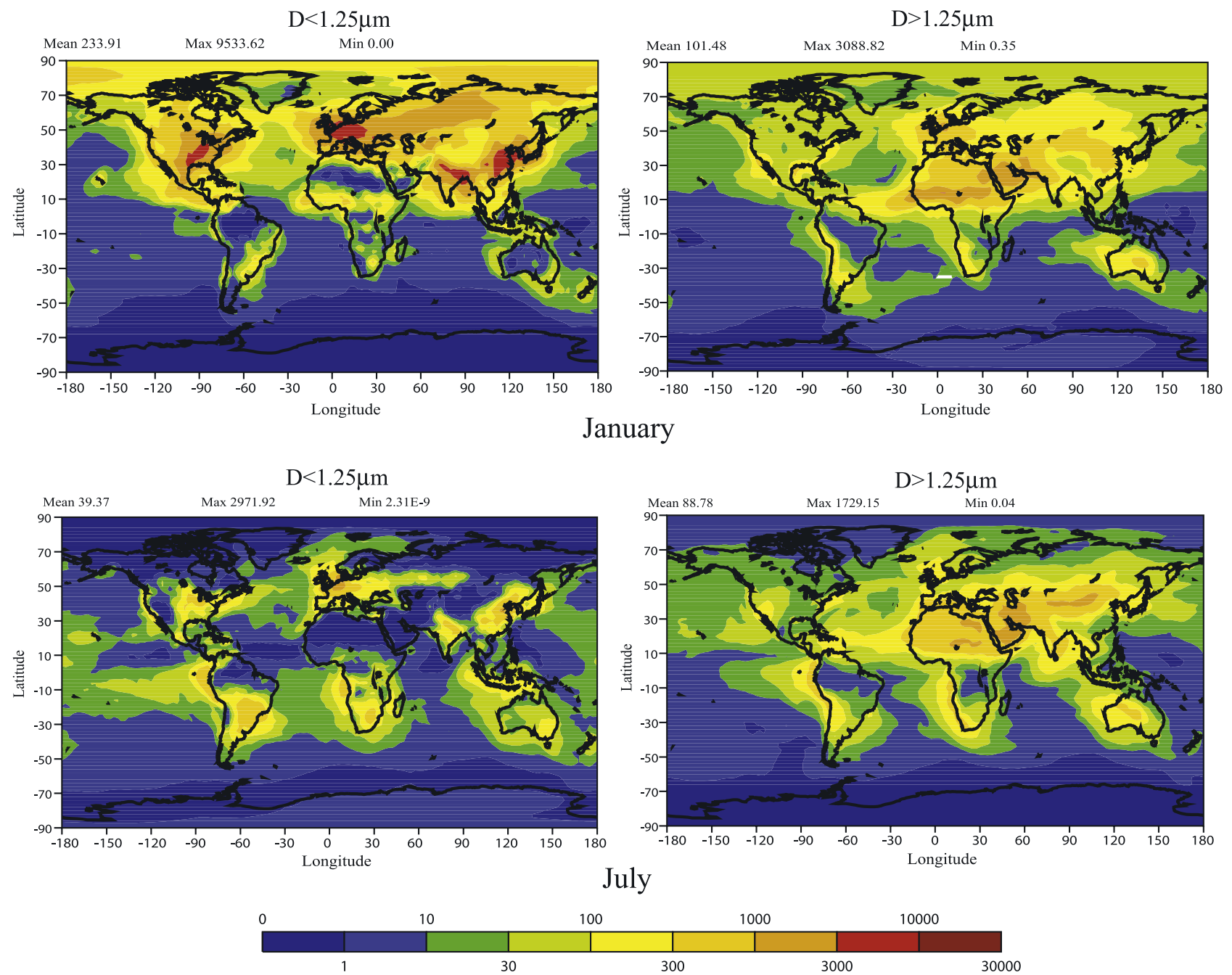

Figure 2. Predicted monthly average mixing ratios (pptv) of nitrate aerosol in the fine mode $(<1.25 \mu \mathrm{m}$ diameter) and the coarse mode $(>1.25 \mu \mathrm{m}$ diameter) near the surface (averaged over the model lowest three layers), in January and July. The maximum, average and minimum values of mixing ratios are indicated above each panel.

ratios, e.g., $1 \mu \mathrm{g} / \mathrm{m}^{3} \mathrm{NO}_{3}^{-}=400 \mathrm{pptv}$ at $298 \mathrm{~K}$ and 1 bar. In January, fine-mode nitrate mixing ratios exceed 1 ppbv over Europe, eastern China, and the eastern United States. In these regions, nitrate aerosol exists mainly as neutralized ammonium nitrate, in an amount that is determined by thermodynamic equilibrium. In July, the increase of sulfate aerosol in the Northern Hemisphere $(\mathrm{NH})$ due to the enhanced oxidation of $\mathrm{SO}_{2}$ reduces the fine-mode nitrate formation significantly, because ammonia reacts preferentially with sulfate which significantly lowers the nitrate aerosol concentrations. In addition, large areas with a significant amount of the fine-mode nitrate concentrations (over $300 \mathrm{pptv})$ are present at high latitudes $\left(>50^{\circ} \mathrm{N}\right)$ in the $\mathrm{NH}$ in January. This nitrate is formed primarily through the hydrolysis of $\mathrm{N}_{2} \mathrm{O}_{5}$ on the surface of sulfate aerosols under low temperatures at night. This heterogeneous production of nitrate aerosol is not that important in July because of the rapid photolysis and thermal decomposition of $\mathrm{N}_{2} \mathrm{O}_{5}$. Marine concentrations of the fine-mode nitrate aerosol are mostly lower than 100 pptv.
[28] Coarse-mode nitrate aerosol concentrations exceeding $1 \mathrm{ppbv}$ are predicted near the surface in dust source regions including central Africa, and the Asian and Australian deserts. Biomass burning areas in central Africa have the largest coarse-mode nitrate concentrations, up to $3 \mathrm{ppbv}$ in January. When the nitrogen sources from biomass burning shift southward in July, nitrate mixing ratios in central Africa are reduced to $300 \mathrm{pptv}$. Nitrate on coarse aerosols over the Asian dust region increases from 300-1000 pptv in January to $1000-3000$ pptv in July as a result of the larger dust fluxes in the spring and summer in this region. Marine concentrations of coarse-mode nitrate are mostly larger than that in the fine mode.

[29] Figure 3 shows the fraction of nitrate aerosol in the fine-mode near the surface in January and July, respectively. Close to the deserts, less than $10 \%$ of the nitrate aerosol is associated with the fine particles in both January and July. In July, the fine-mode nitrate contributes to less than $50 \%$ of the total nitrate aerosol except for the most polluted continents. Figure 4 shows the fraction of total nitrate (gas plus aerosol) occurring as aerosol at surface in January and July 


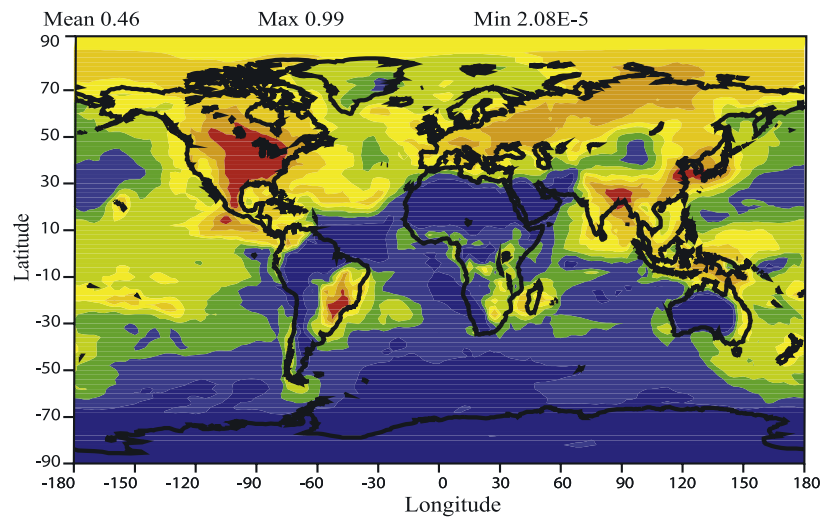

(a) January

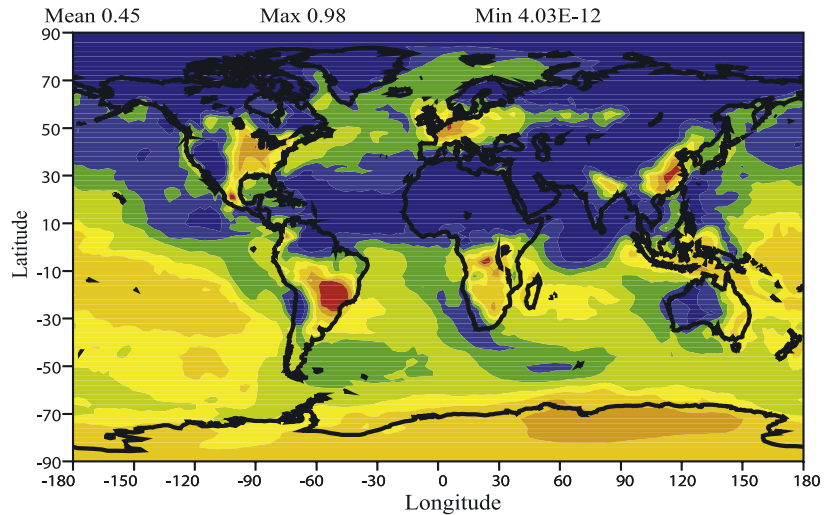

(b) July

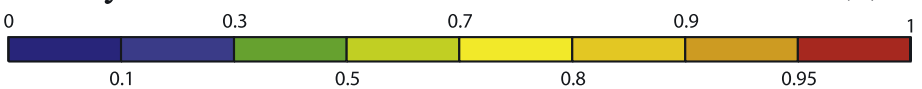

Figure 3. Ratio of the fine-mode nitrate to total aerosol nitrate: $\left[\mathrm{NO}_{3}^{-}(\mathrm{D}<1.25 \mu \mathrm{m})\right] /\left[\mathrm{NO}_{3}^{-}(\mathrm{D}<\right.$ $\left.1.25 \mu \mathrm{m})+\mathrm{NO}_{3}^{-}(\mathrm{D}>1.25 \mu \mathrm{m})\right]$, near the surface in (a) January and (b) July. The maximum, average and minimum values of ratios are indicated above each panel.

(i.e., $\left.\left[\mathrm{NO}_{3}^{-}\right] /\left[\mathrm{NO}_{3}^{-}+\mathrm{HNO}_{3}(\mathrm{~g})\right]\right)$. For both months, the nitrate present on coarse particles determines the largest fractions of aerosol nitrate. At locations with high concentrations of sea salt or dust aerosol, more than $50 \%$ of the total nitrate exists in the aerosol phase. Aerosol nitrate fractions over the Asian deserts, the Arabian Peninsula, the Sahara, and over an extended area over the North Atlantic, approach to $100 \%$. In these regions, the partitioning of nitrate into aerosol is limited only by the availability of nitric acid.

[30] The annual and zonal average $\mathrm{HNO}_{3}(\mathrm{~g})$ and nitrate aerosol $\left(\mathrm{NO}_{3}^{-}\right)$mixing ratios are shown in Figure 5. The largest nitrate aerosol concentrations (over 500 pptv) occur at midlatitudes in the $\mathrm{NH}$ near the surface and drop rapidly toward the SH or as altitude increases. The concentrations of $\mathrm{HNO}_{3}(\mathrm{~g})$ decrease less dramatically than nitrate aerosol as a function of altitude because of the production of
$\mathrm{HNO}_{3}(\mathrm{~g})$ from $\mathrm{NO}_{\mathrm{x}}$ sources in the free troposphere. $\mathrm{HNO}_{3}(\mathrm{~g})$ mixing ratios exceed 200 pptv in the middle and upper troposphere north of $30^{\circ} \mathrm{S}$.

\subsection{Ammonium Aerosol}

[31] Predicted monthly average mixing ratios of ammonium aerosol, for $\mathrm{D}<1.25 \mu \mathrm{m}$ and $\mathrm{D}>1.25 \mu \mathrm{m}$, are shown in Figure 6 for January and July. The highest ammonium mixing ratios, over $3 \mathrm{ppbv}$, are found in agricultural or industrialized areas, such as the eastern United States, Europe, and China. Biomass burning areas in South America and South Africa also have high concentrations of ammonium, about 1 ppbv. Less than $10 \%$ of the total ammonium aerosol is found on coarse particles over most regions, except for the Sahel region where the fraction of coarse-mode ammonium aerosol exceeds $50 \%$. In general, the alkaline compounds of sea salt and dust aerosol make it difficult for $\mathrm{NH}_{3}(\mathrm{~g})$ to partition into coarse particles. The

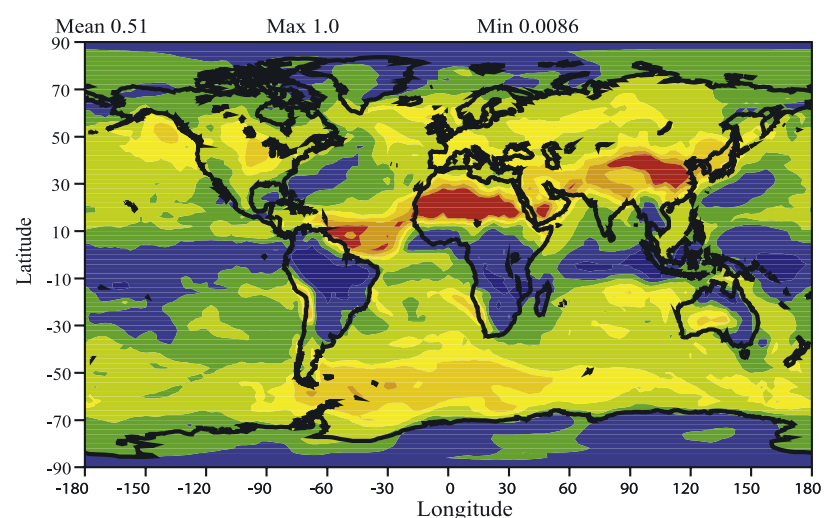

(a) January

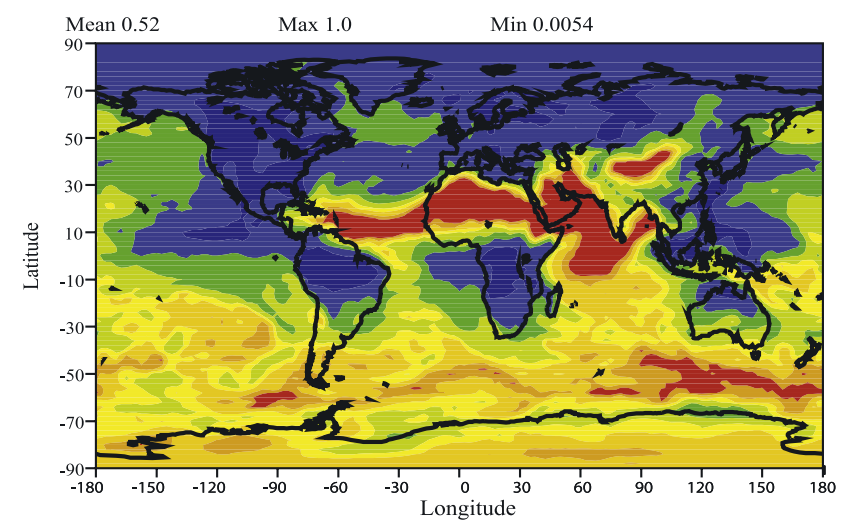

(b) July

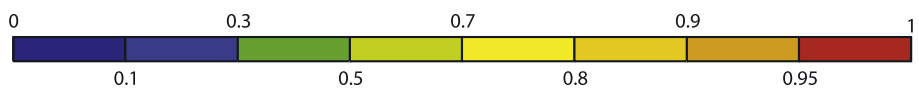

Figure 4. Fraction of nitrate occurring as nitrate aerosol: $\left[\mathrm{NO}_{3}^{-}\right] /\left[\mathrm{NO}_{3}^{-}+\mathrm{HNO}_{3}(\mathrm{~g})\right]$, near the surface in (a) January and (b) July. The maximum, average and minimum values of fractions are indicated above each panel. 

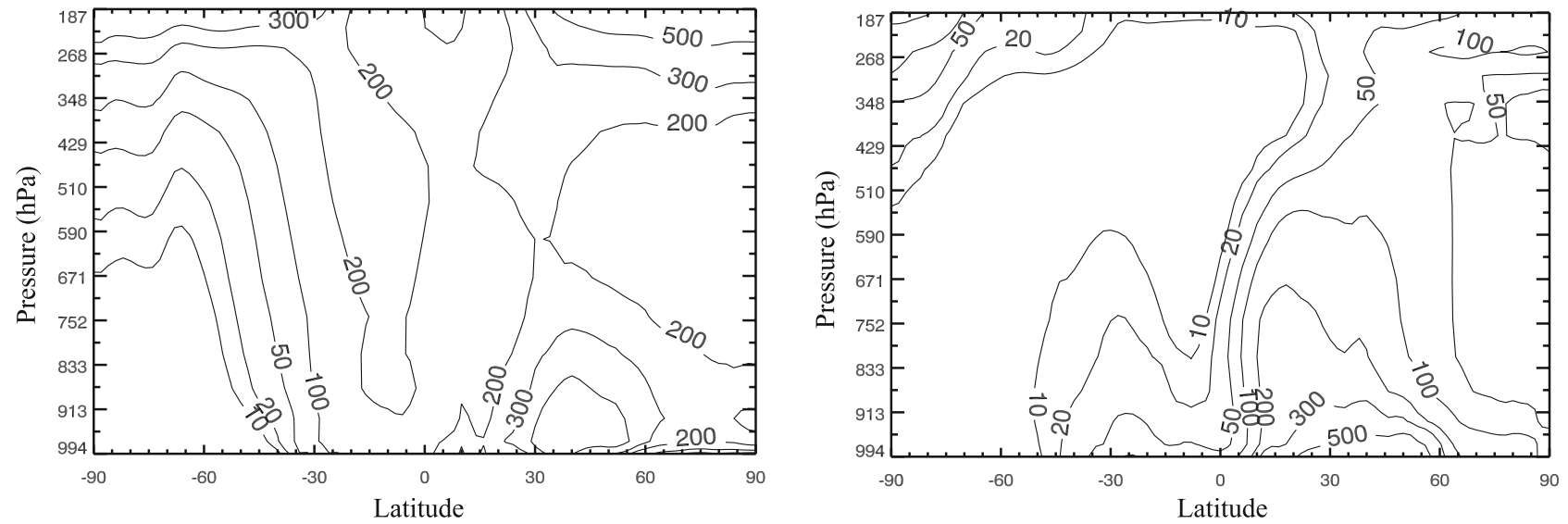

Figure 5. Annual and zonal average $\mathrm{HNO}_{3}(\mathrm{~g})$ and $\mathrm{NO}_{3}^{-}$mixing ratios (pptv).
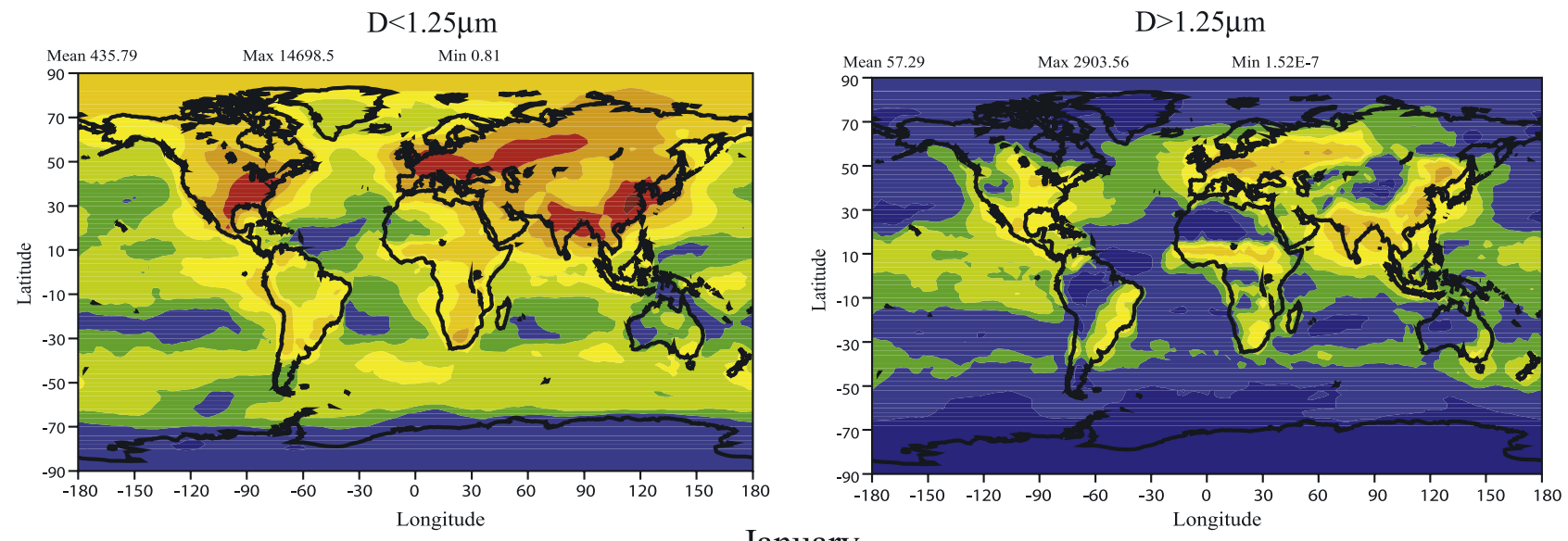

January
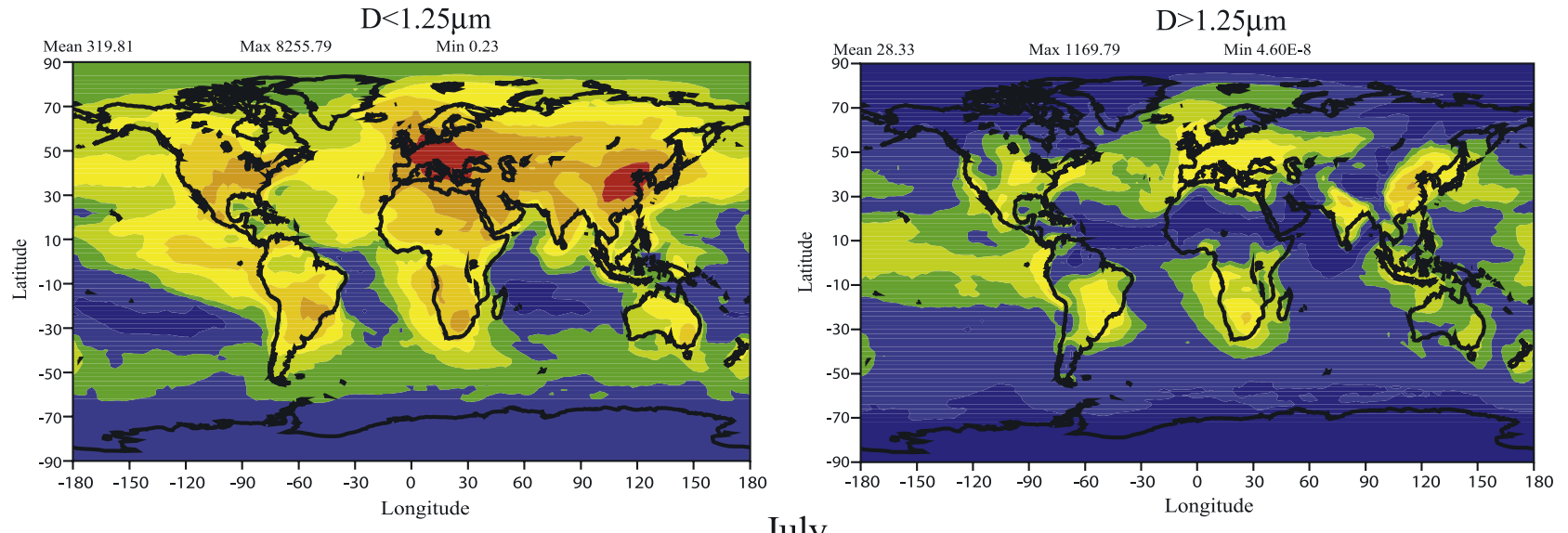

July

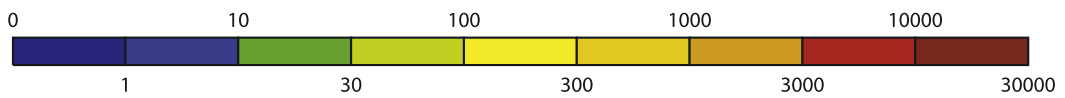

Figure 6. Predicted monthly average mixing ratios (pptv) of ammonium aerosol with (left) diameter $<$ $1.25 \mu \mathrm{m}$ and (right) diameter $>1.25 \mu \mathrm{m}$ near the surface (averaged over the model lowest three layers), in January and July. The maximum, average and minimum values of mixing ratios near the surface are indicated above each panel. 


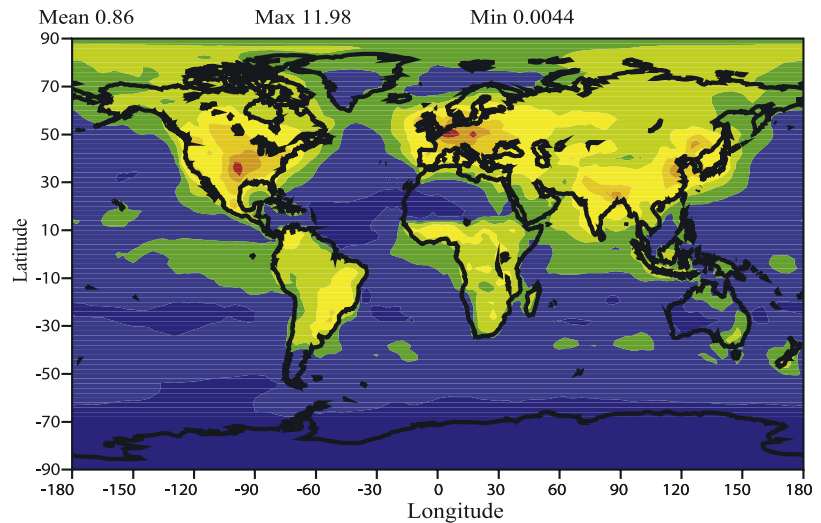

(a) January

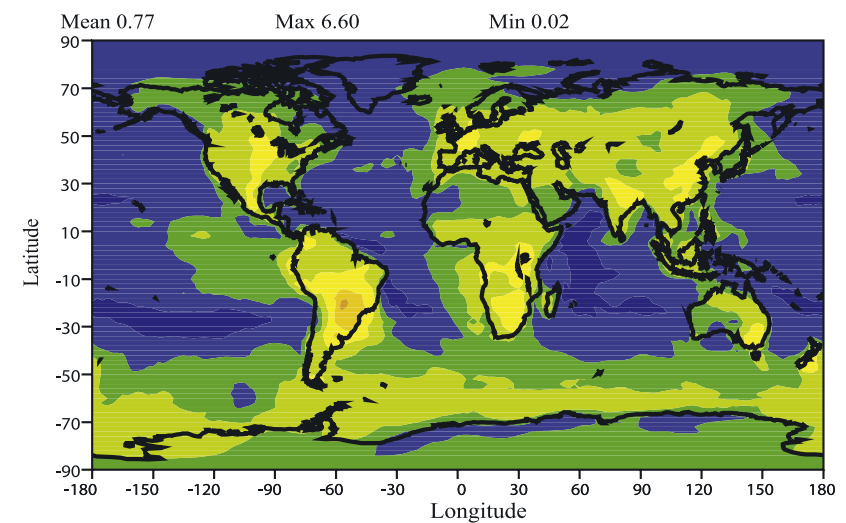

(b) July

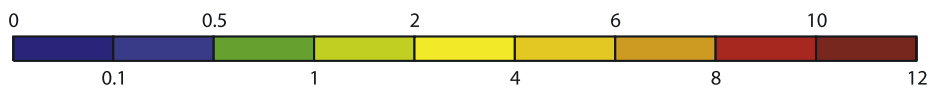

Figure 7. Molar ratios of ammonium aerosol to sulfate aerosol $\left(\mathrm{NH}_{4}^{+} / \mathrm{SO}_{4}^{2-}\right)$ in the lowest three layers for January and July. The maximum, average and minimum values of ratios are indicated above each panel.

mixing ratios of ammonium aerosol generally exceed 300 pptv over the remote continents.

[32] Figure 7 shows the calculated molar ratio of ammonium aerosol to sulfate aerosol $\left(\mathrm{NH}_{4}^{+} / \mathrm{SO}_{4}^{2-}\right)$ near the surface (lowest three layers) in January and July. Most global aerosol models assume that ammonium aerosol is present on sulfate aerosol with a molar ratio to sulfate of 2 . While this assumption is probably good for remote continental regions, there are much higher molar ratios of ammonium to sulfate in the polluted regions because of the presence of aerosol nitrate, especially in the NH in January (exceeding 10:1 in Europe). Therefore the assumption of a constant molar ratio of 2 for $\mathrm{NH}_{4}^{+} / \mathrm{SO}_{4}^{2-}$ could significantly bias a calculation of forcing by anthropogenic aerosols.

[33] The fraction of ammonia occurring in the aerosol phase in the lowest three layers of the model is shown in
Figure 8 . Over $50 \%$ of total ammonia (gas plus aerosol) partitions into the aerosol phase over polluted continents with as much as $100 \%$ at high latitudes due to low temperatures. Aerosol ammonium has a longer residence time in the atmosphere than gas-phase ammonia, so it plays a key role in determining the $\mathrm{pH}$ values of cloud condensation nuclei and precipitation.

[34] Annual and zonal average ammonia and ammonium aerosol mixing ratios are shown in Figure 9. In contrast to $\mathrm{HNO}_{3}(\mathrm{~g})$ and nitrate aerosol, ammonia mixing ratios decrease more rapidly with altitude than does ammonium aerosol. This is because there are no additional $\mathrm{NH}_{3}(\mathrm{~g})$ sources available in the free atmosphere. Moreover, the lower temperatures at high altitudes make it easier to condense ammonia on sulfate aerosol, which partly compensates for the decrease of the available particles at these

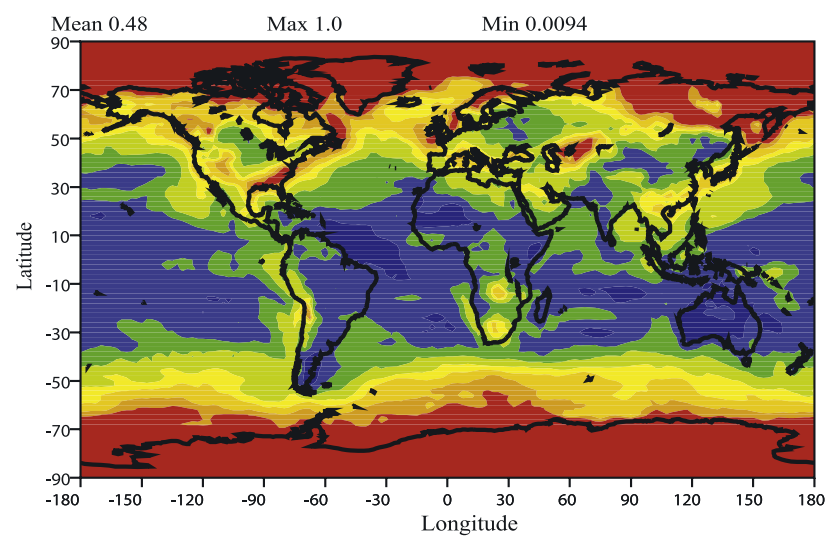

(a) January

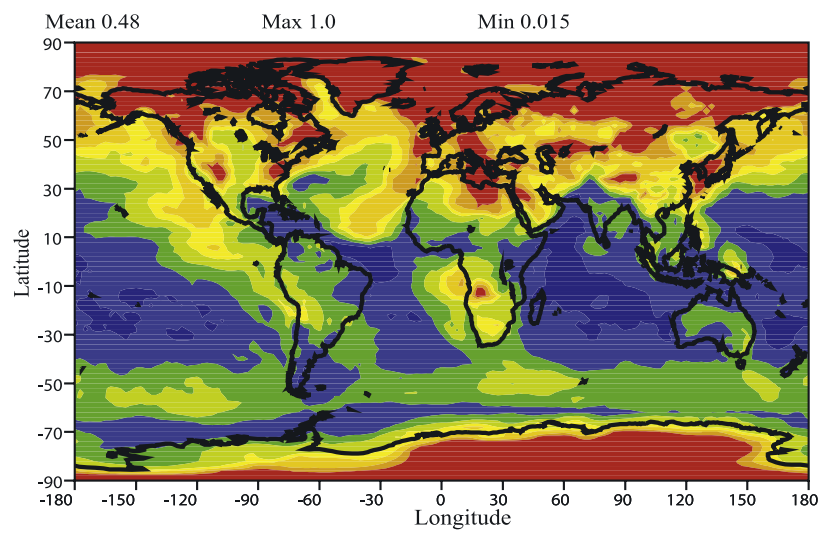

(b) July

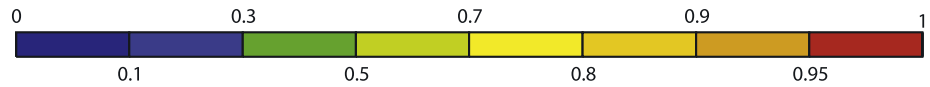

Figure 8. Fraction of total ammonia near the surface occurring as aerosol: $\left[\mathrm{NH}_{4}^{+}\right] /\left[\mathrm{NH}_{4}^{+}+\mathrm{NH}_{3}(\mathrm{~g})\right]$, in (a) January and (b) July. The maximum, average and minimum values of fractions are indicated above each panel. 

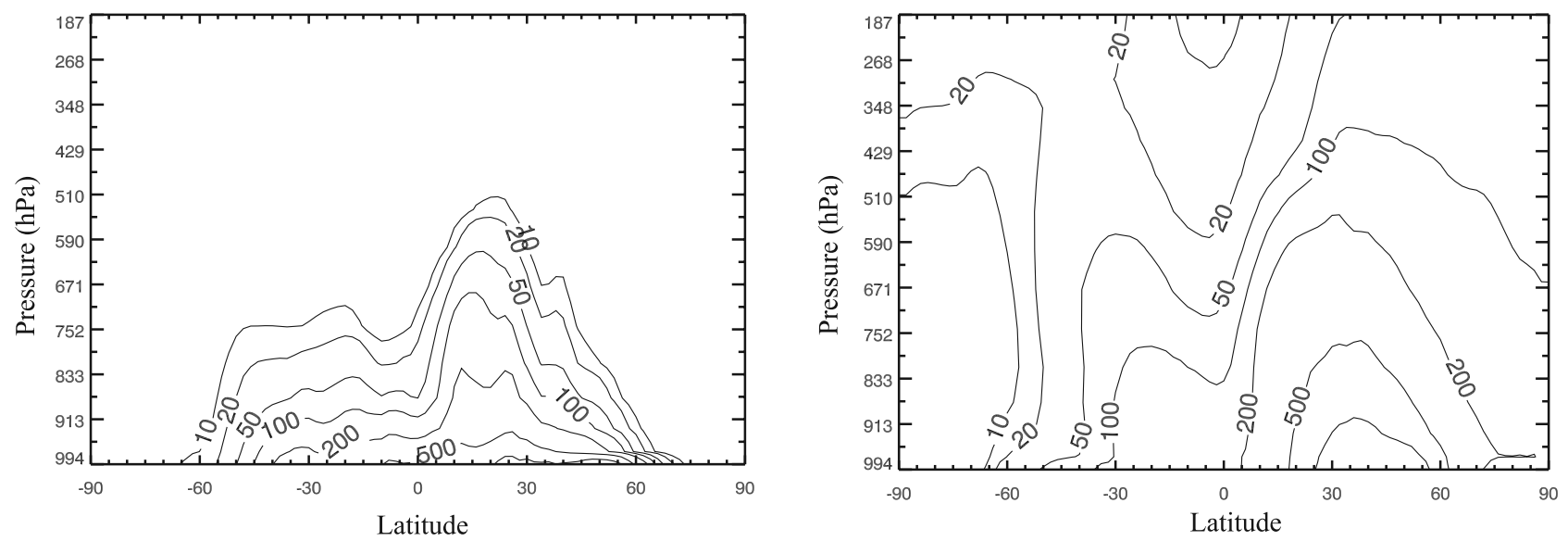

Figure 9. Annual and zonal average $\mathrm{NH}_{3}(\mathrm{~g})$ and $\mathrm{NH}_{4}^{+}$mixing ratios (pptv).

high altitudes. Above $500 \mathrm{hPa}$, almost $100 \%$ of $\mathrm{NH}_{3}(\mathrm{~g})$ is converted to $\mathrm{NH}_{4}^{+}$aerosol.

\subsection{Comparison of Aerosol Concentrations With Ground-Based Measurements}

[35] Comparison of the modeled and observed monthly average sulfate, ammonium and nitrate aerosol concentrations at a series of marine sites is shown in Figures 10a and $10 \mathrm{~b}$ for January and July, respectively. The surface observations were provided by D. Savoie and J. Prospero (University of Miami). Predicted sulfate aerosol concentrations are generally in good agreement with the measurements, except that the model overpredicts sulfate at all stations south of $34^{\circ} \mathrm{S}$ in January.

[36] The surface concentration of ammonium aerosol is mainly determined by the $\mathrm{NH}_{3}$ emissions and the uptake by sulfate aerosol. For most of the stations at which sulfate concentrations are in good agreement with observations, good agreement of the ammonium aerosol is also obtained, e.g., at Bermuda (BER) and Hedo Okinawa, Japan (HOK). However, large deviations from observations are found in the predicted ammonium concentrations for stations such as Cheju, Korea (CHE), even though there are good predictions for sulfate. One of the possible reasons is that, since it appears that higher temperatures in July tend to make $\mathrm{NH}_{3}$ emissions (e.g., from the volatilization of animal wastes) higher than those in January in the NH, the use of constant annual average $\mathrm{NH}_{3}$ emission rates in the model leads to a high bias in the $\mathrm{NH}_{3}$ emissions in January and a low bias in July, compared to the actual emissions. This assumption was necessary because of our limited knowledge of the $\mathrm{NH}_{3}$ inventory. As a result, the model may overpredict the ammonium concentration in January and underpredict it in July, compared to observations. This may also help to explain the overestimated ammonium concentration at Mace Head, Ireland (MAH), in January; in July, the underestimation in the $\mathrm{NH}_{3}$ emission was offset by the overestimated local sulfate aerosol concentration, resulting a good prediction of the ammonium aerosol concentration at MAH.

[37] The model predictions for nitrate aerosol concentrations are mostly within a factor of 2 of the measured concentrations. The concentrations of aerosol nitrate are closely tied to ammonium and sulfate aerosols as well as sea salt aerosol (not shown here), so that it is more difficult to analyze the reasons for differences. In addition, most of the available nitrate (gas plus aerosol) over the oceans is from long-range transport that originates in polluted continental regions. Since the meteorological fields used in this model study may be different from those when the measurements were taken, this could cause differences between the predicted nitrate aerosol concentrations and the observations. A more detailed analysis (using emissions and observations for the same year as our meteorology) would be needed for a better understanding of the discrepancies, but this is beyond the scope of this paper.

[38] Aerosol concentrations are also compared with two ground-based measurement data sets that represent polluted continental conditions: EMEFS and EMEP. The EMEFS (Eulerian Model Evaluation Field Study) data set includes daily aerosol measurements made between 1988 and 1990 at approximately 130 sites spread throughout eastern North America [McNaughton and Vet, 1996]. Following Adams et al. [1999], we examined the computed annual average sulfate, ammonium, and nitrate aerosol concentrations for 75 of these locations ranging from $27^{\circ} \mathrm{N}$ to $57^{\circ} \mathrm{N}$ in latitude, and from $65^{\circ} \mathrm{W}$ to $107^{\circ} \mathrm{W}$ in longitude. The EMEP (European Monitoring and Evaluation Programme) reported measurements are obtained in Europe as annual averages that span from 1986 to 1995 [Hjellbrekke and Hanssen, 1998]. Because the EMEP data represents a 22-year time period during which the pollutant emissions have changed, we compared our model results only with the annual averages in 1986, when the sulfur emissions and the predicted sulfate concentrations most closely match the reported values. This facilitates the comparison of ammonium and nitrate aerosol with observations. There were 69 EMEP stations that reported annual average concentrations for sulfate aerosol, while 17 sites reported concentrations for ammonium aerosol, and only 12 sites reported concentrations for nitrate aerosol. These stations are located between $37^{\circ} \mathrm{N}$ and $74^{\circ} \mathrm{N}$ in latitude and between $29^{\circ} \mathrm{E}$ and $21^{\circ} \mathrm{W}$ in longitude.

[39] Figure 11 shows a comparison between the simulated and available observed aerosol concentrations (converted to the equivalent gaseous volume mixing ratios) for sulfate, ammonium, and nitrate at the continental sites from the two data sets. For sulfate, all of the model predictions fall within a factor of 2 of the measurements at the EMEFS sites while 

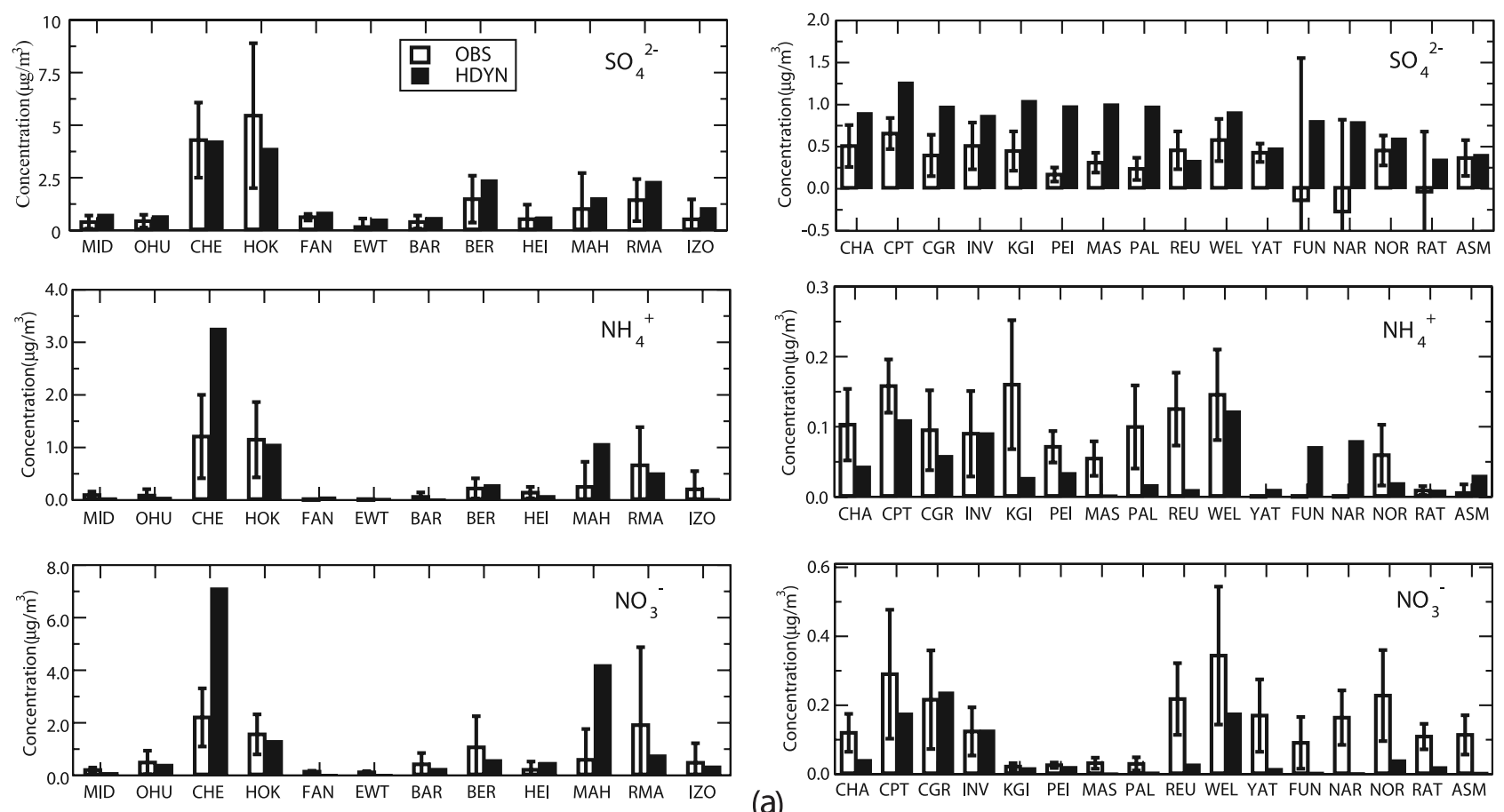

(a)
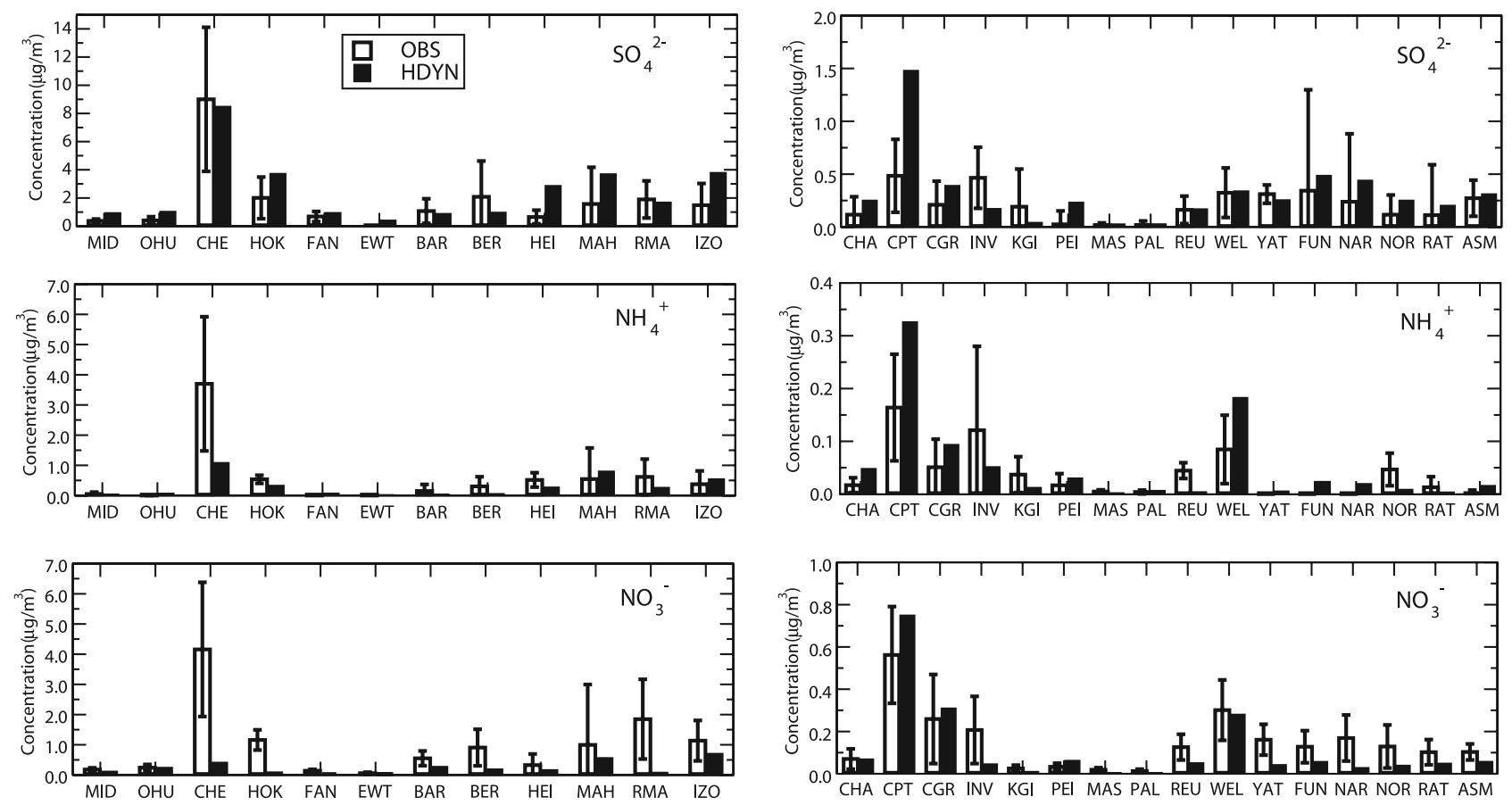

(b)

Figure 10. (a) Observed and modeled average concentrations of sulfate, ammonium, and nitrate aerosol in January, at marine stations in the NH, MID $\left(28.22^{\circ} \mathrm{N}, 177.35^{\circ} \mathrm{W}\right)$, OHU $\left(21.33^{\circ} \mathrm{N}, 157.7^{\circ} \mathrm{W}\right), \mathrm{CHE}$ $\left(33.52^{\circ} \mathrm{N}, 126.48^{\circ} \mathrm{E}\right)$, $\operatorname{HOK}\left(26.92^{\circ} \mathrm{N}, 128.25^{\circ} \mathrm{E}\right)$, FAN $\left(3.92^{\circ} \mathrm{N}, 159.33^{\circ} \mathrm{W}\right)$, EWT $\left(11.33^{\circ} \mathrm{N}, 162.33^{\circ} \mathrm{E}\right)$, BAR $\left(13.17^{\circ} \mathrm{N}, 59.43^{\circ} \mathrm{W}\right)$, BER $\left(32.27^{\circ} \mathrm{N}, 64.87^{\circ} \mathrm{W}\right)$, HEI $\left(63.4^{\circ} \mathrm{N}, 20.3^{\circ} \mathrm{W}\right), \mathrm{MAH}\left(53.32^{\circ} \mathrm{N}, 9.85^{\circ} \mathrm{W}\right)$, RMA $\left(25.75^{\circ} \mathrm{N}, 80.25^{\circ} \mathrm{W}\right)$, and IZO $\left(28.30^{\circ} \mathrm{N}, 16.50^{\circ} \mathrm{W}\right)$ and in the $\mathrm{SH}, \mathrm{CHA}\left(43.92^{\circ} \mathrm{S}, 176.5^{\circ} \mathrm{W}\right)$, CPT $\left(34.35^{\circ} \mathrm{S}, 18.48^{\circ} \mathrm{E}\right), \mathrm{CGR}\left(40.68^{\circ} \mathrm{S}, 144.68^{\circ} \mathrm{E}\right), \mathrm{INV}\left(46.43^{\circ} \mathrm{S}, 168.35^{\circ} \mathrm{E}\right), \mathrm{KGI}\left(62.18^{\circ} \mathrm{S}, 58.3^{\circ} \mathrm{W}\right)$, PEI $\left(46.92^{\circ} \mathrm{S}, 37.75^{\circ} \mathrm{E}\right)$, MAS $\left(67.6^{\circ} \mathrm{S}, 62.5^{\circ} \mathrm{E}\right)$, PAL $\left(64.77^{\circ} \mathrm{S}, 64.05^{\circ} \mathrm{W}\right)$, REU $\left(21.17^{\circ} \mathrm{S}, 55.83^{\circ} \mathrm{E}\right)$, WEL $\left(41.28^{\circ} \mathrm{S}, 174.87^{\circ} \mathrm{E}\right)$, YAT $\left(22.15^{\circ} \mathrm{S}, 167.0^{\circ} \mathrm{E}\right)$, FUN $\left(8.5^{\circ} \mathrm{S}, 179.2^{\circ} \mathrm{W}\right)$, NAR $\left(0.53^{\circ} \mathrm{S}, 166.95^{\circ} \mathrm{E}\right)$, NOR $\left(29.08^{\circ} \mathrm{S}, 167.98^{\circ} \mathrm{E}\right)$, RAT $\left(21.25^{\circ} \mathrm{S}, 159.75^{\circ} \mathrm{W}\right)$, and ASM $\left(14.25^{\circ} \mathrm{S}, 170.58^{\circ} \mathrm{W}\right)$. Observation data were provided by D. Savoie and J. Prospero (University of Miami). (b) As in Figure 10a but for July. 

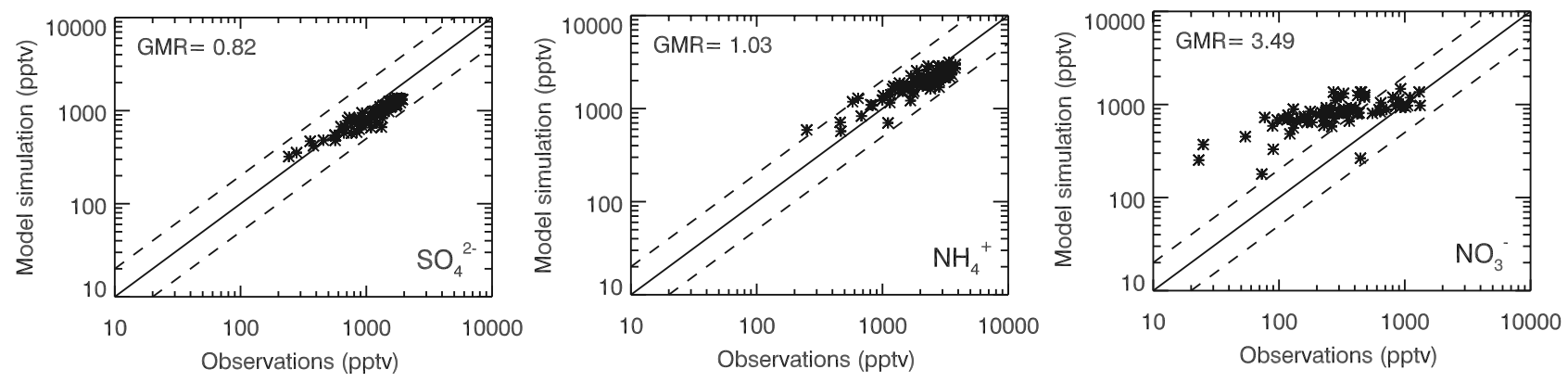

(a) EMEFS sites (North America)
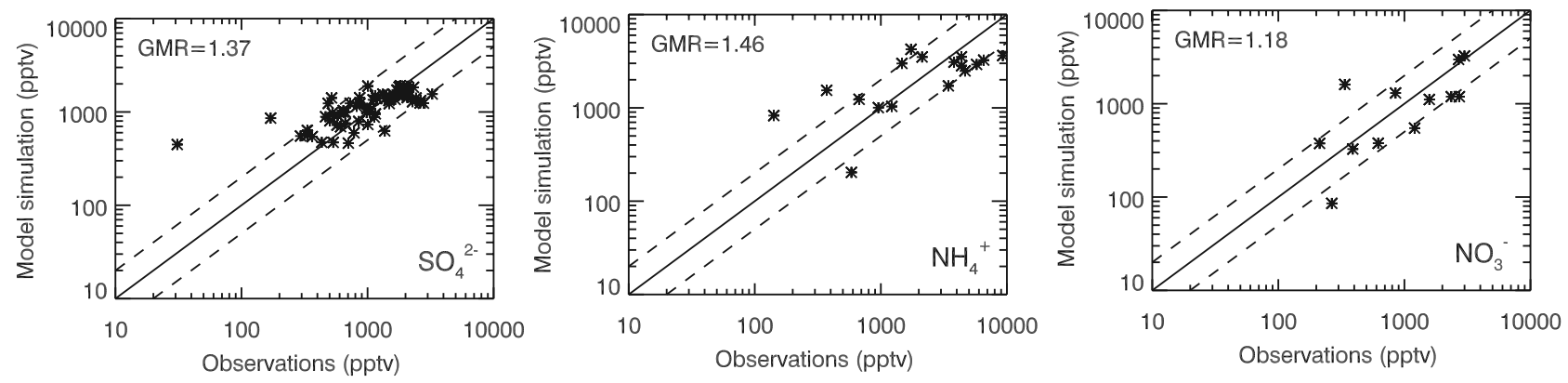

(b) EMEP sites (Europe)

Figure 11. Observed and modeled annual average concentrations (shown in their equivalent gaseous volume mixing ratios, pptv) of sulfate, ammonium, and nitrate aerosols at polluted continental sites from the (a) EMEFS (North America) and (b) EMEP (Europe) databases. Dashed lines indicate 2:1 and $1: 2$ ratios. The geometric mean over all the ratios of modeled to observed mixing ratios (GMR) is indicated in each plot.

$94 \%$ are within a factor of 2 at the EMEP sites. In North America, the model systematically underestimates observations by about $18 \%$ on average, but the scatter between the observations and the model prediction is small. In contrast, there is more scatter between the observations and the model predictions at the European sites and the model overestimates the observations by $37 \%$ on average.

[40] The calculated ammonium aerosol concentration agrees extremely well with the EMEFS data. The geometric mean of the ratios of the model predictions over the observations for the 75 EMEFS stations is nearly 1 . The predicted ammonium aerosol concentrations are slightly higher than the EMEP observations, which are available at much fewer sites. Excessive ammonium sulfate formation in the model may contribute to the overpredicted ammonium, since the calculated sulfate aerosol concentrations are also high compared with the EMEP observations.

[41] The agreement between the calculated and the observed nitrate aerosol concentration is poor at the North American sites. A possible reason is that, as stated in Adams et al. [1999], particulate nitrate may evaporate from filter packs, and the resulting measurements may be biased low by as much as 24\% [Pakkanen et al., 1999]. While 10 out of 12 model predictions fall within a factor of 2 of the European observations, only $27 \%$ of the data obtained at the 75 North American sites do so. In North America, the model especially tends to overestimate nitrate aerosol at sites with low levels of the nitrate observations (below 400-500 pptv). One possible explanation is that the model predicted less sulfate than it should have at these sites.

\subsection{Global Budgets}

[42] The global and annual average budgets of nitrate and ammonium aerosol in the troposphere (i.e., the layers below $200 \mathrm{hPa}$ ) and their net mass conversion rates to/from their gaseous precursors are summarized in Figure 12. The $\mathrm{HNO}_{3}$ tropospheric burden is computed to be $0.37 \mathrm{Tg} \mathrm{N}$. The net chemical production of $\mathrm{HNO}_{3}$ from gas-phase chemistry plus heterogeneous conversion from $\mathrm{N}_{2} \mathrm{O}_{5}$ on aerosols is $35.8 \mathrm{Tg} \mathrm{N} \mathrm{yr}^{-1}$ (i.e., 14.6 $\mathrm{Tg} \mathrm{N} \mathrm{yr}^{-1}$ from conversion of $\mathrm{N}_{2} \mathrm{O}_{5}, 26.0 \mathrm{Tg} \mathrm{N} \mathrm{yr}{ }^{-1}$ from reaction of $\mathrm{NO}_{2}$ with $\mathrm{OH}$, and $4.8 \mathrm{Tg} \mathrm{N} \mathrm{yr}^{-1}$ loss through photolysis and reaction with $\mathrm{OH}$ ), which is $92 \%$ of the total $\mathrm{NO}_{\mathrm{x}}$ emissions (38.9 $\mathrm{Tg} \mathrm{N} \mathrm{yr}^{-1}$ ). $32 \%$ of the $\mathrm{HNO}_{3}$ removal is due to the formation of aerosol nitrate including $4.6 \mathrm{Tg} \mathrm{N} \mathrm{yr}^{-1}$ in the fine-mode and 7.1 $\mathrm{Tg} \mathrm{N} \mathrm{yr}^{-1}$ in the course-mode. The calculated annual nitrate aerosol burden is $0.16 \mathrm{Tg} \mathrm{N}$, with a lifetime of 5 days.

[43] Figure 12 suggests an important link to tropospheric ozone chemistry. Most of the current global gas-phase chemistry models only consider the heterogeneous conversion of $\mathrm{N}_{2} \mathrm{O}_{5}$ to $\mathrm{HNO}_{3}$ on aerosols [e.g., Dentener and Crutzen, 1993; Dentener et al., 1996; Tie et al., 2003]. Since the formation of aerosol nitrate directly removes $\mathrm{HNO}_{3}$, the inclusion of this process could further enhance the decrease of tropospheric ozone due to the loss of $\mathrm{NO}_{\mathrm{x}}$. On the basis of this study, the calculated nitrate aerosol burden $(0.16 \mathrm{Tg} \mathrm{N})$ is about $43 \%$ of the $\mathrm{HNO}_{3}$ burden $(0.37 \mathrm{Tg} \mathrm{N})$ on a global and annual average basis. This means that the conversion of $\mathrm{HNO}_{3}$ back to $\mathrm{NO}_{x}$ is reduced by about $43 \%$ when the formation of nitrate aerosol is included. In Figure 12, the 


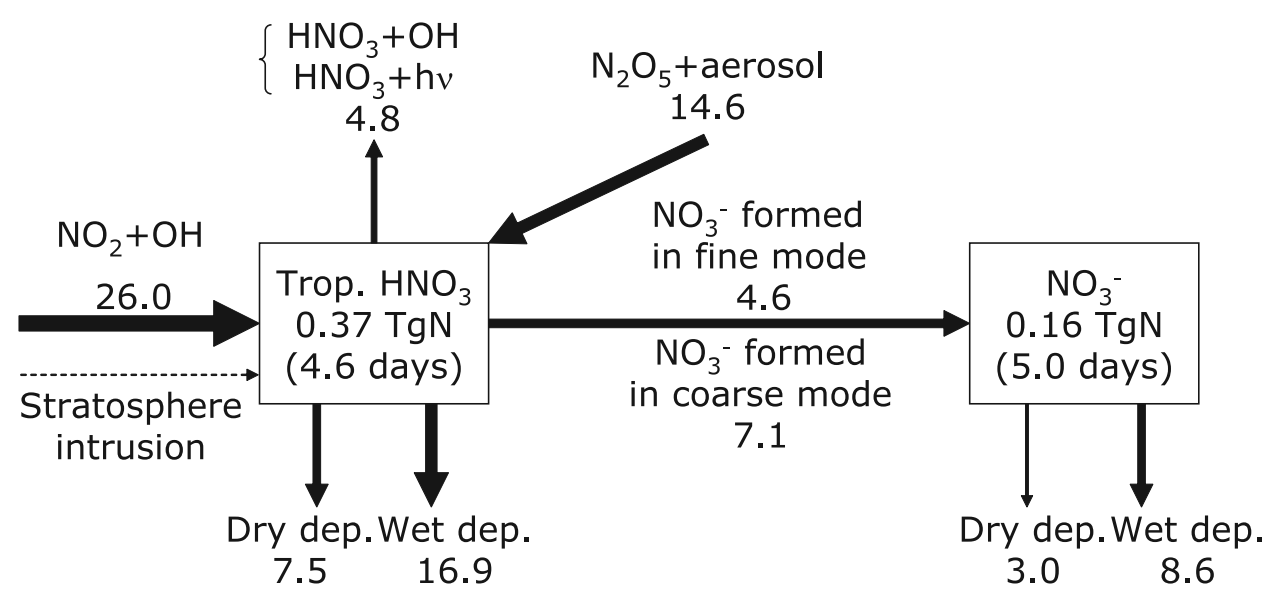

Nitrate

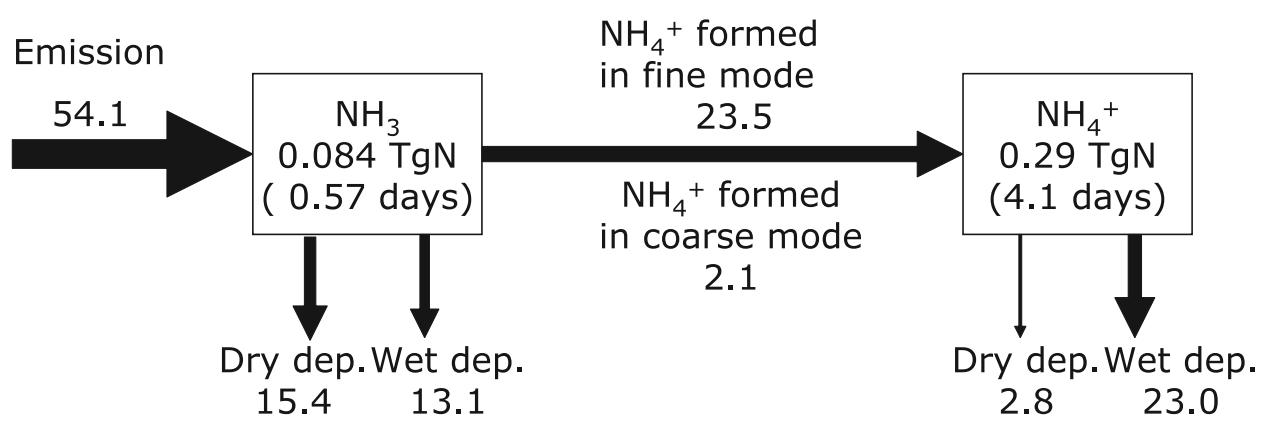

Ammonium

Figure 12. Schematic diagram of the global and annual budgets of nitrate and ammonium calculated in the Umich/IMPACT model. Burdens are in $\mathrm{Tg} \mathrm{N}$, and lifetimes are shown inside the boxes. Arrows indicate emissions, deposition fluxes, and net conversion rates in $\mathrm{Tg} \mathrm{N}$ per year.

recycling of $\mathrm{NO}_{\mathrm{x}}$ from $\mathrm{HNO}_{3}\left(4.8 \mathrm{Tg} \mathrm{N} \mathrm{yr}^{-1}\right)$ is as much as $12 \%$ of the tropospheric $\mathrm{NO}_{\mathrm{x}}$ emissions $\left(38.9 \mathrm{Tg} \mathrm{N} \mathrm{yr}^{-1}\right)$. Thus the omission of nitrate aerosol will underestimate the $\mathrm{NO}_{\mathrm{x}}$ loss rate due to heterogeneous reactions on aerosol by $5 \%$ (i.e., $43 \%$ of $12 \%$ ) and therefore overpredict the tropospheric ozone concentrations to a similar extent. The impact on tropospheric nitrogen oxides and ozone may be more significant on a regional scale.

[44] For ammonia, nearly half of the $54.1 \mathrm{Tg} \mathrm{N}$ per year which is emitted is taken up by aerosols, with about $92 \%$ on the fine-mode aerosols (Figure 12). While $\mathrm{NH}_{3}$ is removed more efficiently by dry deposition, $89 \%$ of the aerosol $\mathrm{NH}_{4}^{+}$ is removed by wet deposition. The lifetime of aerosol $\mathrm{NH}_{4}^{+}$, 4.1 days, is much longer than that of $\mathrm{NH}_{3}, 0.57$ days.

\section{Sensitivity Study Using the Thermodynamic Equilibrium Assumption}

[45] In order to examine the difference between the HDYN simulations and a model that considers only thermodynamic equilibrium, we replaced the HDYN method in the Umich/IMPACT model with a multisize-sectional thermodynamic equilibrium model [Jacobson, 1999] to calculate aerosol nitrate and ammonium (EQ). In other words, the assumption of the establishment of the thermodynamic equilibrium between the gas and the aerosol phases is extended from the submicron aerosols only to aerosol particles over the entire aerosol size range. Except for this change, the other components of the global model remained the same as in the simulations with the HDYN method. The EQ model is about 4 times slower than a bulk-aerosol equilibrium model and 30\% slower than the HDYN model, because the main computational effort in the HDYN method is to calculate the surface vapor concentration which is based on the aqueous-phase equilibrium only and is much faster than the gas-aerosol equilibrium calculation. Since it is computationally expensive, we have only run the equilibrium model for January and July. The average of January and July is a reasonable approximation to the annual average results.

[46] Figure 13 shows a comparison of the calculated $\mathrm{HNO}_{3}(\mathrm{~g})$ and nitrate aerosol burdens for the two methods. For this comparison, results for the HDYN model were also averaged over January and July. The EQ model produces a fine-mode nitrate aerosol burden of $0.059 \mathrm{Tg} \mathrm{N}$, which is $25 \%$ lower than that of HDYN, $0.079 \mathrm{Tg} \mathrm{N}$. This underestimation of fine-mode nitrate aerosol is solely due to the different partitioning methods used for nitrate and ammonium in the global model. This sensitivity study demonstrates that direct forcing estimates based on aerosol 


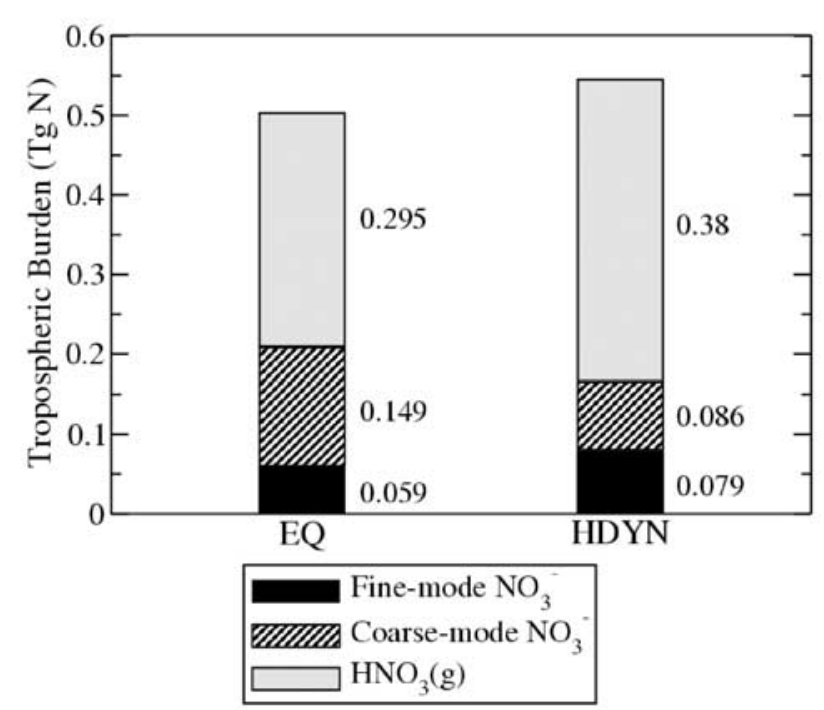

Figure 13. Comparison of the $\mathrm{HNO}_{3}$ gas and nitrate aerosol burdens $(\mathrm{Tg} \mathrm{N})$ between an equilibrium calculation and the more accurate HDYN method in the Umich/ IMPACT model. Averages of the January and July results are shown for both methods.

concentrations at equilibrium will be significantly underpredicted since the fine-model aerosol is the most efficient at scattering solar radiation. The EQ method also calculates a much higher nitrate aerosol burden in the coarse mode and a smaller tropospheric $\mathrm{HNO}_{3}$ burden, compared to that of HDYN. Moreover, the total nitrate burden (gas plus aerosol) calculated by EQ is nearly $8 \%$ lower than that of HDYN. This suggests that the total nitrate in EQ is removed more efficiently since the same $\mathrm{NO}_{\mathrm{x}}$ emissions and chemistry were used for both EQ and HDYN. This is due to a much larger dry deposition $\left(8.17 \mathrm{Tg} \mathrm{N} \mathrm{yr}^{-1}\right)$ and a moderately larger wet $\left(11.72 \mathrm{Tg} \mathrm{N} \mathrm{yr}^{-1}\right)$ deposition of nitrate aerosol in EQ, compared to that in HDYN $\left(3.5 \mathrm{Tg} \mathrm{N} \mathrm{yr}^{-1}\right.$ and 9.0 $\mathrm{Tg} \mathrm{N} \mathrm{yr}^{-1}$, respectively). Although EQ predicts more nitrate aerosols, these nitrates are associated with much larger aerosols than those of HDYN so they are removed faster through both dry and wet deposition. The lifetime of nitrate aerosol calculated by EQ is 3.8 days, and it is shorter than the 5 days predicted by HDYN, as a result of the overpredicted global nitrogen deposition.

[47] The global distribution of the nitrate and ammonium aerosol surface mixing ratios calculated by the thermodynamic equilibrium model is shown in Figure 14 for January and July. Compared to the HDYN method for nitrate (results shown in Figure 2), the EQ model significantly overpredicts coarse-mode nitrate aerosol concentrations (by as much as a factor of 3 ) over most of the model domain for both January and July. On the other hand, the EQ model predicts lower fine-mode nitrate aerosol concentrations than does the HDYN model because of the shift of nitrate aerosol to coarse aerosol particles during the establishment of equilibrium. The global average fine-mode nitrate aerosol mixing ratio in July is reduced by more than a half, from $39.4 \mathrm{pptv}$ in HDYN to $18.8 \mathrm{pptv}$ in the equilibrium model. This effect is especially significant on the remote continents or over the oceans, where the availability of the total nitrate is limited. In the polluted regions where sufficient nitrate is available, the fine-mode nitrate aerosol concentrations are less affected, while the coarse-mode concentrations still increase substantially. Therefore the total nitrate aerosol concentrations in these regions are overestimated by the equilibrium model, compared to those of the HDYN method. At some locations, e.g., over the Arabian Peninsula and the central African deserts in July, assuming thermodynamic equilibrium results in less nitrate on the coarse aerosols compared to that calculated considering the mass transport limitation. This is because in the equilibrium calculation nitrate was associated with the largest dust particles which deposit quickly, whereas in HDYN the nitrate first diffuses into the smallest size bin of the coarse mode. When solid nitrate salts are formed in that bin, the associated nitrate aerosol cannot be transported to coarser particles. Thus the coarse-mode nitrate in HDYN has a longer residence time than does the coarse-mode nitrate in the equilibrium model.

[48] Figure 14 also shows the global distribution of ammonium aerosol mixing ratios calculated by the equilibrium model in January and July. Similar to the differences noted above for nitrate aerosol, the equilibrium model mostly underpredicts the fine-mode ammonium aerosol mixing rations and overpredicts those in the coarse mode compared to the HDYN method (compare to Figure 6). However, the overall effect is much smaller, because ammonium is mainly associated with the fine-mode aerosols where the thermodynamic equilibrium assumption is frequently valid. Under dry relative humidity conditions when solid ammonium salts form, e.g., over the Indian Peninsula in July, lower coarse-mode ammonium concentrations are calculated for the equilibrium model.

\section{Comparison With Other Model Studies \\ 5.1. Global Budgets}

[49] Table 3 summarizes the comparison of the global budgets calculated by the hybrid dynamical model in this work with previous model studies. The nitrate aerosol burden predicted here $(0.16 \mathrm{Tg} \mathrm{N})$ is slightly smaller than the $0.18 \mathrm{Tg} \mathrm{N}$ given by Liao et al. [2004] (L04), but both of these values are much smaller than that calculated by Rodriguez and Dabdub [2004] (RD04), 0.42 Tg N. Also the calculated nitrate aerosol lifetime (5 days) is shorter than the 7.7 days calculated by RD04 but comparable to the lifetime calculated by L04 (4.9 days). This is probably because the assumption of gas-aerosol equilibrium in the bulk model used by RD04 favors the formation of the finemode nitrate aerosol.

[50] Table 3 also shows that there are large differences in the dry and wet deposition of nitrate aerosol between different global model studies. RD04 removes nitrate aerosol predominantly through wet deposition, while L04 removes it primarily by dry deposition. The total deposition by HDYN in this work is similar to that of L04, but $74 \%$ is through wet deposition compared to $43 \%$ in L04. One of reasons for these differences is that different model treatments for nitrate in aerosol result in nitrate being in different particle size ranges. Coarse-mode nitrate is removed more efficiently by dry deposition, while fine-mode nitrate is removed primarily through wet deposition. The ratio 
$\mathrm{D}<1.25 \mu \mathrm{m}$

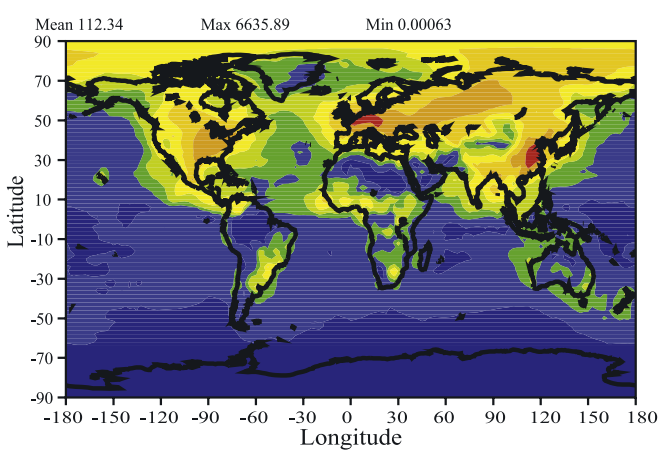

$\mathrm{D}>1.25 \mu \mathrm{m}$

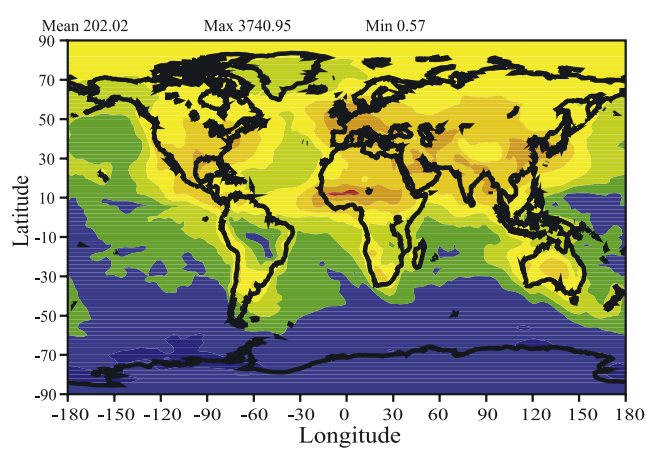

January: $\mathrm{NO}_{3}^{-}$
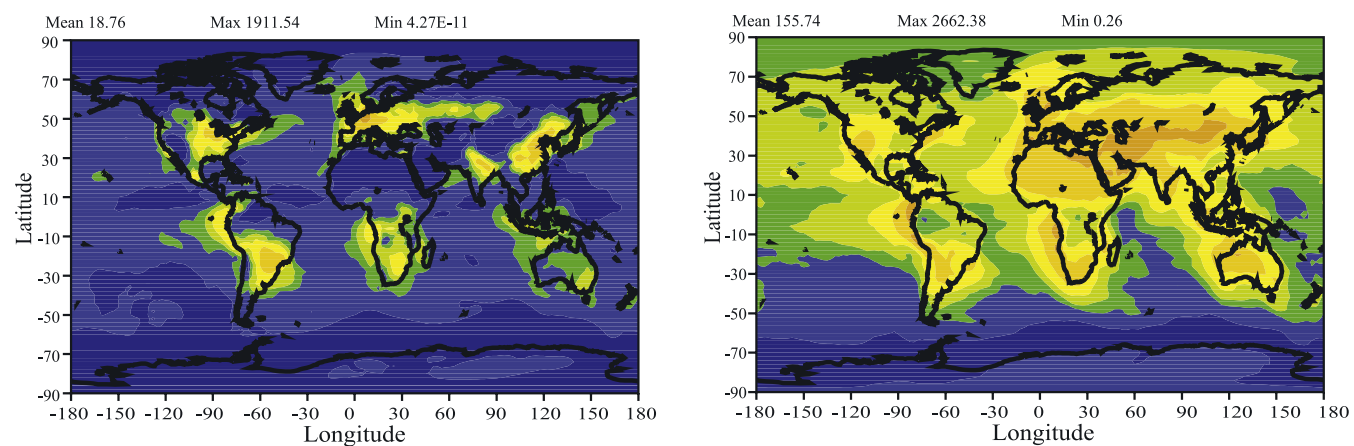

July: $\mathrm{NO}_{3}$
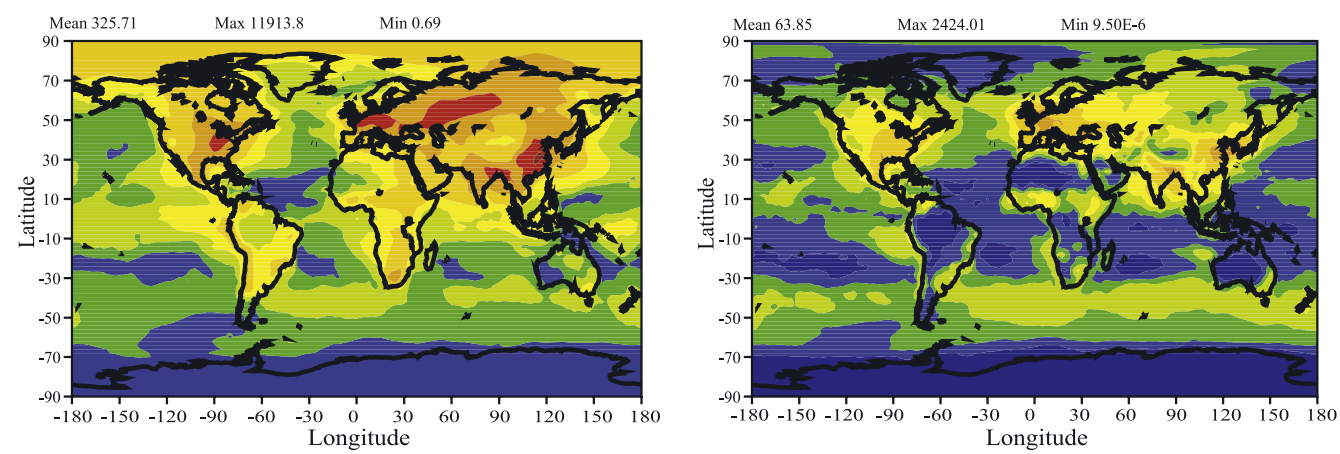

January: $\mathrm{NH}_{4}^{+}$
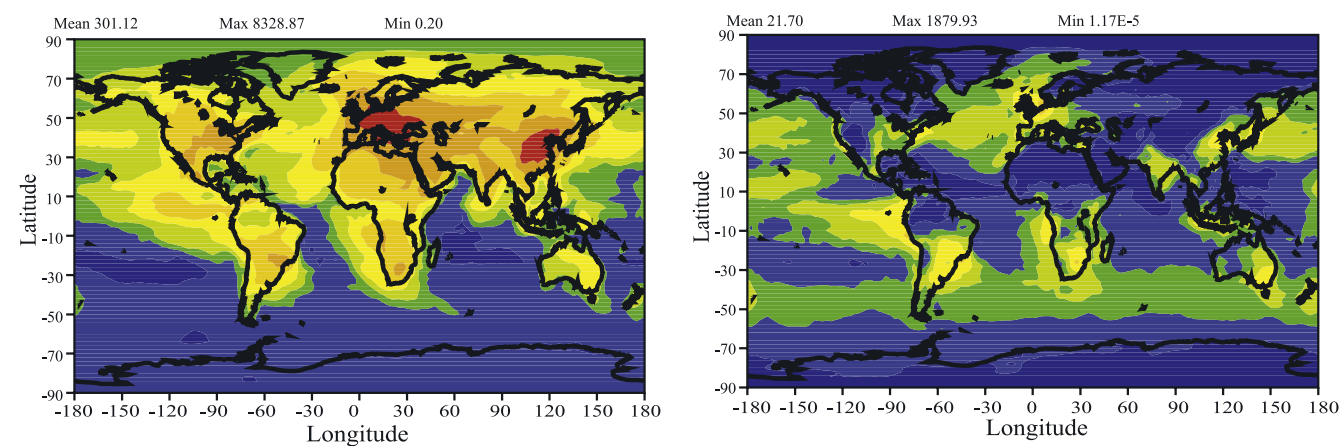

July: $\mathrm{NH}_{4}^{+}$

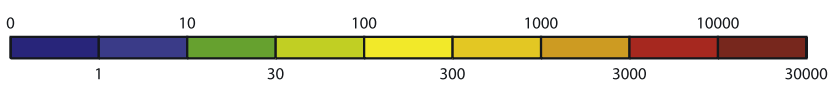

Figure 14. Model predicted aerosol nitrate and ammonium mixing ratios (in pptv) for $\mathrm{D}<1.25 \mu \mathrm{m}$ and $\mathrm{D}>1.25 \mu \mathrm{m}$ for the thermodynamic equilibrium model (compare Figures 2 and 6). 
Table 3. Comparison of Nitrate and Ammonium Global Budgets With Other Studies

\begin{tabular}{|c|c|c|c|c|}
\hline Budget Component & This Work $^{\mathrm{a}}$ & Rodriguez and Dabdub [2004] & Liao et al. [2004] & Adams et al. [1999] \\
\hline \multicolumn{5}{|c|}{ Burden, $\operatorname{Tg} N$} \\
\hline Tropospheric $\mathrm{HNO}_{3}{ }^{\mathrm{b}}$ & 0.37 & & 0.28 & \\
\hline Total $\mathrm{NO}_{3}^{-}$ & 0.16 & 0.42 & 0.18 & 0.029 \\
\hline $\mathrm{NO}_{3}^{-}(\mathrm{D}<1.25 \mu \mathrm{m})$ & 0.067 & & 0.059 & 0.029 \\
\hline $\mathrm{NO}_{3}^{-}(\mathrm{D}>1.25 \mu \mathrm{m})$ & 0.089 & & 0.12 & \\
\hline $\mathrm{NH}_{4}^{+}$ & 0.29 & 0.045 & 0.26 & 0.30 \\
\hline $\mathrm{NH}_{3}$ & 0.084 & 0.19 & 0.19 & 0.14 \\
\hline \multicolumn{5}{|c|}{ Lifetime, days } \\
\hline Tropospheric $\mathrm{HNO}_{3}$ & 4.6 & & 3.7 & \\
\hline $\mathrm{NO}_{3}^{-}$ & 5.0 & 7.7 & 4.9 & \\
\hline $\mathrm{NH}_{4}^{+}$ & 4.1 & 3.6 & & 4.2 \\
\hline $\mathrm{NH}_{3}$ & 0.57 & 1.4 & & 0.93 \\
\hline \multicolumn{5}{|c|}{ Sources, $T g N y r^{-1}$} \\
\hline $\mathrm{NO}_{\mathrm{x}}$ emission & 38.9 & 34.7 & 40.0 & \\
\hline $\mathrm{HNO}_{3}$ net chemical production ${ }^{\mathrm{c}}$ & 35.8 & 29.7 & 28.1 & \\
\hline $\mathrm{NO}_{3}^{-}$production $\left(\mathrm{HNO}_{3} \rightarrow \mathrm{NO}_{3}^{-}\right)$ & 11.6 & 19.8 & 13.6 & \\
\hline $\mathrm{NH}_{4}^{+}$production & 25.7 & 4.5 & & 26.1 \\
\hline $\mathrm{NH}_{3}$ emission & 54.1 & 52.1 & & 53.6 \\
\hline \multicolumn{5}{|c|}{ Deposition, $T g N y r^{-1}$} \\
\hline $\mathrm{HNO}_{3}$ dry deposition & 7.5 & 4.0 & 6.3 & \\
\hline $\mathrm{HNO}_{3}$ wet deposition & 16.9 & 5.9 & 8.4 & \\
\hline $\mathrm{NO}_{3}^{-}$dry deposition & 3.0 & 1.1 & 7.7 & \\
\hline $\mathrm{NO}_{3}^{-}$wet deposition & 8.6 & 18.7 & 5.9 & \\
\hline $\mathrm{NH}_{4}^{+}$dry deposition & 2.8 & 0.20 & & 6.6 \\
\hline $\mathrm{NH}_{4}^{+}$wet deposition & 23.0 & 4.3 & & 19.5 \\
\hline $\mathrm{NH}_{3}$ dry deposition & 15.4 & 29.4 & & 19.0 \\
\hline $\mathrm{NH}_{3}$ wet deposition & 13.1 & 16.7 & & 7.4 \\
\hline
\end{tabular}

${ }^{\text {a } R e s u l t s ~ a r e ~ e s t i m a t e d ~ f r o m ~ t h e ~ 4-m o n t h ~(J a n u a r y, ~ A p r i l, ~ J u l y ~ a n d ~ O c t o b e r) ~ s i m u l a t i o n s ~ f o r ~ H D Y N . ~}$

${ }^{\mathrm{b}}$ In this work, the tropospheric $\mathrm{HNO}_{3}$ burden was calculated by summing over the model levels below $200 \mathrm{hPa}$.

${ }^{c}$ Includes $\mathrm{NO}_{2}+\mathrm{OH} \rightarrow \mathrm{HNO}_{3}, \mathrm{HNO}_{3}+\mathrm{OH} \rightarrow \mathrm{NO}_{3}+\mathrm{H}_{2} \mathrm{O}, \mathrm{HNO}_{3} \rightarrow \mathrm{NO}_{2}+\mathrm{OH}$, and $\mathrm{N}_{2} \mathrm{O}_{5}+$ aerosol $\rightarrow 2 \mathrm{HNO}_{3}$.

between the amount of nitrate removed by dry and wet deposition is important because it plays a significant role in determining the global distribution of nitrogen deposition in the atmosphere, which may affect the global carbon cycle in the biosphere [Lamarque et al., 2005].

[51] As shown in the Table 3, the calculated ammonium aerosol lifetime is similar to that calculated by RD04 (3.6 days) and Adams et al. [1999] (A99, 4.2 days). The omission of sea salt and dust aerosol in A99 resulted in a slightly longer lifetime and larger burden for aerosol $\mathrm{NH}_{4}^{+}$ than that in this work, since $\mathrm{NH}_{4}^{+}$is mainly taken up by sulfate and nitrate aerosols. However, the $\mathrm{NH}_{3}$ lifetime calculated in A99 (0.93 days) and RD04 (1.4 days) are both much longer than that in this study ( 0.57 days). The larger $\mathrm{NH}_{3}$ wet deposition in this study seems to contribute to our shorter lifetime, although the effective Henry's law constant for $\mathrm{NH}_{3}$ that was used in the wet deposition scheme $\left(1.05 \times 10^{6} \mathrm{M} \mathrm{atm}^{-1}\right)$ of our model is actually smaller than the value used in A99 $\left(3.3 \times 10^{6} \mathrm{M} \mathrm{atm}^{-1}\right)$. Our wet deposition scheme for gases and the precipitation rates from the assimilated meteorology data are expected to lead to different results from the GCM wet deposition treatment and precipitation used in A99. To compare with $\mathrm{RD} 04$, their equilibrium assumption limited the $\mathrm{NH}_{4}^{+}$production to only $4.5 \mathrm{Tg} \mathrm{N} \mathrm{yr}^{-1}$, which is less than $1 / 5$ of that in this work. Because the alkaline compounds in sea salt and dust aerosol are all available to compete for nitrate since there is no consideration of the mass transport limitation in $\mathrm{RD} 04$, less nitrate is available to neutralize the ammonium. This causes a much lower conversion of $\mathrm{NH}_{3}$ to $\mathrm{NH}_{4}^{+}$in
RD04 and a much longer lifetime for $\mathrm{NH}_{3}$ than that in this study.

\subsection{Treatment for Nitrate and Ammonium Aerosols}

[52] In addition to the thermodynamic equilibrium assumption that is already examined in the sensitivity study (section 4), there are two other approaches commonly used to account for aerosol nitrate and ammonium in global models. They are a first-order removal approximation based on uptake coefficients (hereafter referred to as UPTAKE) as described in the section 2.4, and a simple hybrid approach (hereafter referred to as HYB), which adopts the UPTAKE method for nitrate uptake by dust aerosol and assumes gasaerosol equilibrium on either sulfate aerosols [Liao et al., 2003] or sulfate and sea salt aerosols [Liao et al., 2004]. Besides these partitioning methods used to treat aerosol nitrate and ammonium, other aspects in global models, such as emissions, deposition schemes, and meteorological fields, etc., can also contribute to the differences between model studies. This makes it difficult to fully understand the cause of these differences.

[53] In order to eliminate the effects of these other factors, we implemented both the UPTAKE and the HYB methods in our global transport model (Umich/IMPACT), following that the methods used by Bauer et al. [2004] and Liao et al. [2003], respectively. These studies considered the interaction of nitrate with dust aerosols using the UPTAKE method [Bauer et al., 2004] or with sulfate and dust aerosols using the HYB method [Liao et al., 2003]. We made the same assumptions here. We did not consider the uptake of $\mathrm{N}_{2} \mathrm{O}_{5}$ 
Table 4. Comparison of Aerosols Considered and Nitrate Global Budget ${ }^{\mathrm{a}}$ Between the HDYN, HYB, and UPTAKE Methods

\begin{tabular}{|c|c|c|c|}
\hline & HDYN & HYB & UPTAKE \\
\hline Aerosol types & sulfate, sea salt, and dust & sulfate and dust & dust \\
\hline \multicolumn{4}{|c|}{ Burden, $\operatorname{Tg} N$} \\
\hline $\mathrm{NO}_{\mathrm{x}}$ (below $200 \mathrm{hPa}$, in $\mathrm{Tg}$ ) & 0.27 & 0.27 & 0.42 \\
\hline $\mathrm{HNO}_{3}$ (below $200 \mathrm{hPa}$ ) & 0.38 & 0.31 & 0.20 \\
\hline Total $\mathrm{NO}_{3}^{-}$ & 0.17 & 0.25 & 0.35 \\
\hline $\mathrm{NO}_{3}^{-}(\mathrm{D}<1.25 \mu \mathrm{m})$ & 0.079 & 0.075 & 0.13 \\
\hline $\mathrm{NO}_{3}^{-}(\mathrm{D}>1.25 \mu \mathrm{m})$ & 0.086 & 0.18 & 0.22 \\
\hline \multicolumn{4}{|c|}{$\mathrm{HNO}_{3}$ Production, $\mathrm{Tg} \mathrm{Nyr}^{-1}$} \\
\hline $\mathrm{NO}_{2}+\mathrm{OH}$ & 28.4 & 28.1 & 35.7 \\
\hline $\mathrm{N}_{2} \mathrm{O}_{5}+$ aerosol & 16.1 & 15.5 & 4.5 \\
\hline \multicolumn{4}{|c|}{$\mathrm{HNO}_{3}$ Loss, $\mathrm{Tg} \mathrm{Nyr} r^{-1}$} \\
\hline $\mathrm{HNO}_{3}+\mathrm{OH}$ and $\mathrm{HNO}_{3}+\mathrm{h} \nu$ & 5.0 & 4.5 & 4.0 \\
\hline Gas-to-aerosol conversion & 12.6 & 14.8 & 20.7 \\
\hline Dry deposition & 8.5 & 8.0 & 5.5 \\
\hline Wet deposition & 17.8 & 16.0 & 10.3 \\
\hline \multicolumn{4}{|c|}{$\mathrm{NO}_{3}^{-}$Production, $\mathrm{Tg} \mathrm{N} \mathrm{yr}^{-1}$} \\
\hline Gas-to-aerosol ( $\mathrm{D}<1.25 \mu \mathrm{m})$ & 5.1 & 3.8 & 7.1 \\
\hline Gas-to-aerosol (D > $1.25 \mu \mathrm{m})$ & 7.5 & 11.3 & 13.9 \\
\hline \multicolumn{4}{|c|}{$\mathrm{NO}_{3}^{-}$Loss, $\mathrm{Tg} \mathrm{N} \mathrm{yr}^{-1}$} \\
\hline Dry deposition & 3.5 & 3.3 & 3.2 \\
\hline Wet deposition & 9.0 & 11.3 & 16.6 \\
\hline
\end{tabular}

and $\mathrm{HNO}_{3}$ by sulfate aerosols in the UPTAKE simulation because the hydrolysis of $\mathrm{HNO}_{3}$ on sulfate aerosol is mainly constrained by thermodynamic equilibrium which is closely tied to the availability of aerosol ammonium and the ambient conditions. Therefore, if the UPTAKE method is applied to sulfate aerosols for nitrate uptake, one would significantly overpredict nitrate on sulfate aerosols; if the UPTAKE method is applied to sulfate aerosol for the $\mathrm{N}_{2} \mathrm{O}_{5}$ uptake only, one would overpredict $\mathrm{HNO}_{3}$ without considering its uptake by sulfate aerosols. We also did not consider uptake of $\mathrm{NO}_{3}^{-}$by sea salt, since no uptake coefficients of $\mathrm{HNO}_{3}$ on sea salt are available. In addition, we chose not to implement the equilibrium assumption for sea salt aerosols made by Liao et al. [2004] because sea salt aerosols are mostly coarse particles and equilibrium would not be appropriate. The uptake coefficients used in UPTAKE and HYB for $\mathrm{HNO}_{3}$ and $\mathrm{N}_{2} \mathrm{O}_{5}$ were 0.1 and 0.05 , respectively. Table 4 compares the online calculated nitrate global budgets for HDYN, HYB, and UPTAKE. Results are shown for the 2-month averages (January and July). Because no dynamical calculations are needed, HYB is about a factor of 4 faster than HDYN. The UPTAKE method takes less than 1.5 hours on 64 IBM SP3 processors to complete a 1-month simulation.

[54] Both UPTAKE and HYB predict lower $\mathrm{HNO}_{3}$ burdens in the troposphere (i.e., 0.20 and $0.31 \mathrm{Tg} \mathrm{N}$, respectively, compared to $0.38 \mathrm{Tg} \mathrm{N}$ in HDYN), and higher nitrate aerosol burdens, (i.e., 0.35 and $0.25 \mathrm{Tg} \mathrm{N}$, respectively, compared to $0.17 \mathrm{Tg} \mathrm{N}$ in HDYN). Therefore the UPTAKE and HYB methods overestimate nitrate in the aerosol phase by $106 \%$ and $47 \%$, respectively. Heterogeneous conversion of $\mathrm{N}_{2} \mathrm{O}_{5}$ to $\mathrm{HNO}_{3}$ calculated by UPTAKE is the lowest of the three methods, only $4.5 \mathrm{Tg} \mathrm{N} \mathrm{yr}^{-1}$. This is mainly because the conversion of $\mathrm{N}_{2} \mathrm{O}_{5}$ to $\mathrm{HNO}_{3}$ on sulfate aerosol is not treated in UPTAKE. The inclusion of sulfate aerosol in HDYN and HYB provides additional large reactive surfaces for $\mathrm{N}_{2} \mathrm{O}_{5}$ conversion. However, UPTAKE still calculates a larger formation rate of aerosol nitrate $\left(\mathrm{NO}_{3}^{-}\right)$from $\mathrm{HNO}_{3}, 20.7 \mathrm{Tg} \mathrm{N} \mathrm{yr}{ }^{-1}$, than does HDYN $\left(12.6 \mathrm{Tg} \mathrm{N} \mathrm{yr}^{-1}\right)$. HYB also overpredicts the nitrate aerosol formation rate but to a lesser extent, because it inserts an upper limit for the uptake of nitrate determined by the available alkalinity of the dust. Since the conversion of $\mathrm{N}_{2} \mathrm{O}_{5}$ to $\mathrm{HNO}_{3}$ removes tropospheric $\mathrm{NO}_{\mathrm{x}}$, the underestimate by UPTAKE leads to a higher $\mathrm{NO}_{\mathrm{x}}$ burden $(0.42 \mathrm{Tg})$ than in HDYN $(0.27 \mathrm{Tg})$, even though it significantly overpredicts the uptake of nitrate by aerosols. As a result, the decrease of tropospheric ozone concentrations due to heterogeneous interactions is probably underestimated in model studies using the UPTAKE method. With HYB, the large overestimation of nitrate aerosol formation reduces $\mathrm{HNO}_{3}$ concentrations but has little impact on the tropospheric $\mathrm{NO}_{\mathrm{x}}$ burden.

[55] Figure 15 shows the geographic distribution of the 2-month average $\mathrm{HNO}_{3}$ and $\mathrm{NO}_{\mathrm{x}}$ mixing ratios calculated by HDYN in the lowest three layers of the model. The ratios of the $\mathrm{HNO}_{3}$ and $\mathrm{NO}_{\mathrm{x}}$ mixing ratios calculated by UPTAKE and $\mathrm{HYB}$ to those of HDYN are also shown. High $\mathrm{HNO}_{3}$ concentrations exist over the $\mathrm{NO}_{\mathrm{x}}$ source regions such as the industrialized areas in the $\mathrm{NH}$ and biomass burning areas in the SH. The remote continental and marine concentrations of $\mathrm{HNO}_{3}$ exceed $30-100$ pptv because of long-range transport. The ratios of the $\mathrm{HNO}_{3}$ mixing ratios from UPTAKE or HYB to that of HDYN are as low as 0.1 over the Arabian Peninsula, portions of the Sahara, and the Australian deserts, suggesting an excessive nitrate uptake by dust aerosols in these two methods. Without the conversion of $\mathrm{N}_{2} \mathrm{O}_{5}$ on sulfate aerosol, UPTAKE underpredicts $\mathrm{HNO}_{3}$ concentrations relative to HDYN by a factor of 2 more than does HYB, especially at mid and high latitudes in 
$\mathrm{HNO}_{3}: \mathrm{HDYN}$
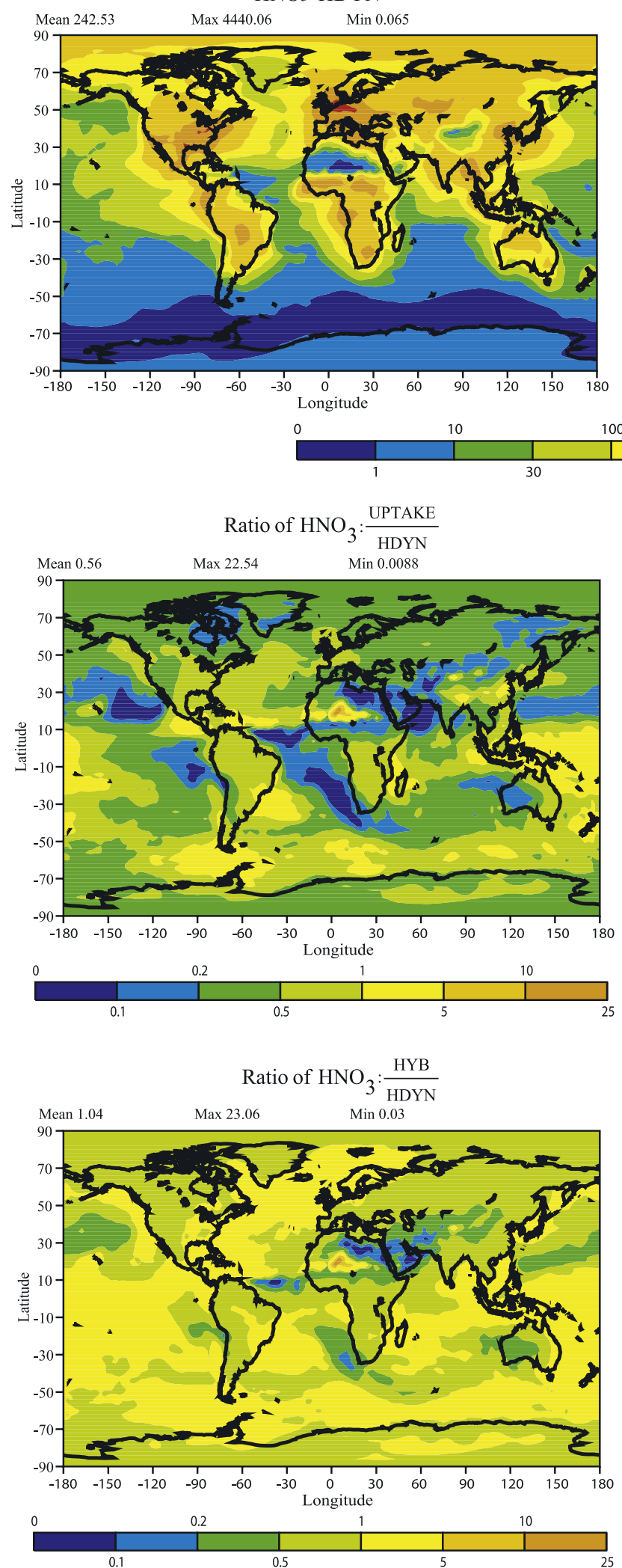

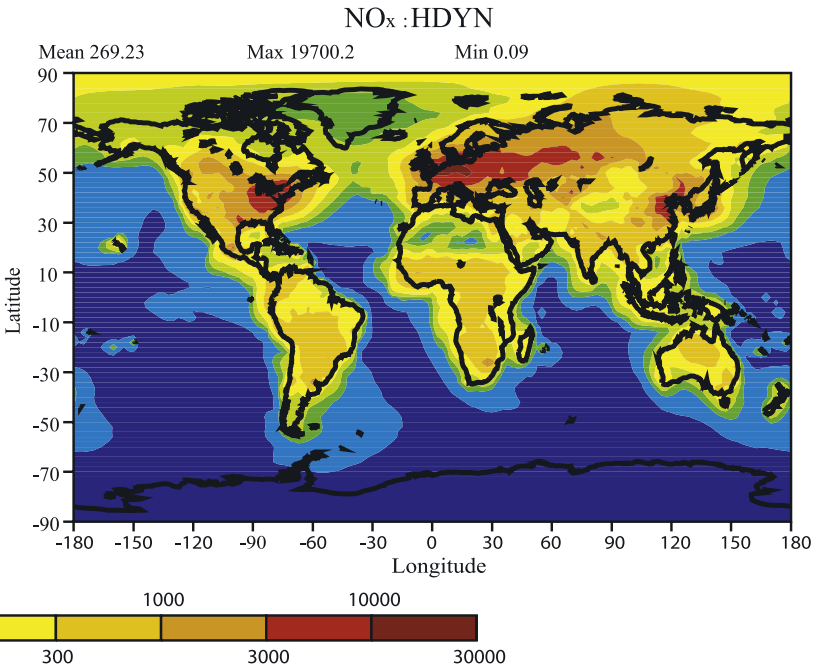

Ratio of $\mathrm{NO}_{\mathrm{X}}: \frac{\text { UPTAKE }}{\mathrm{HDYN}}$
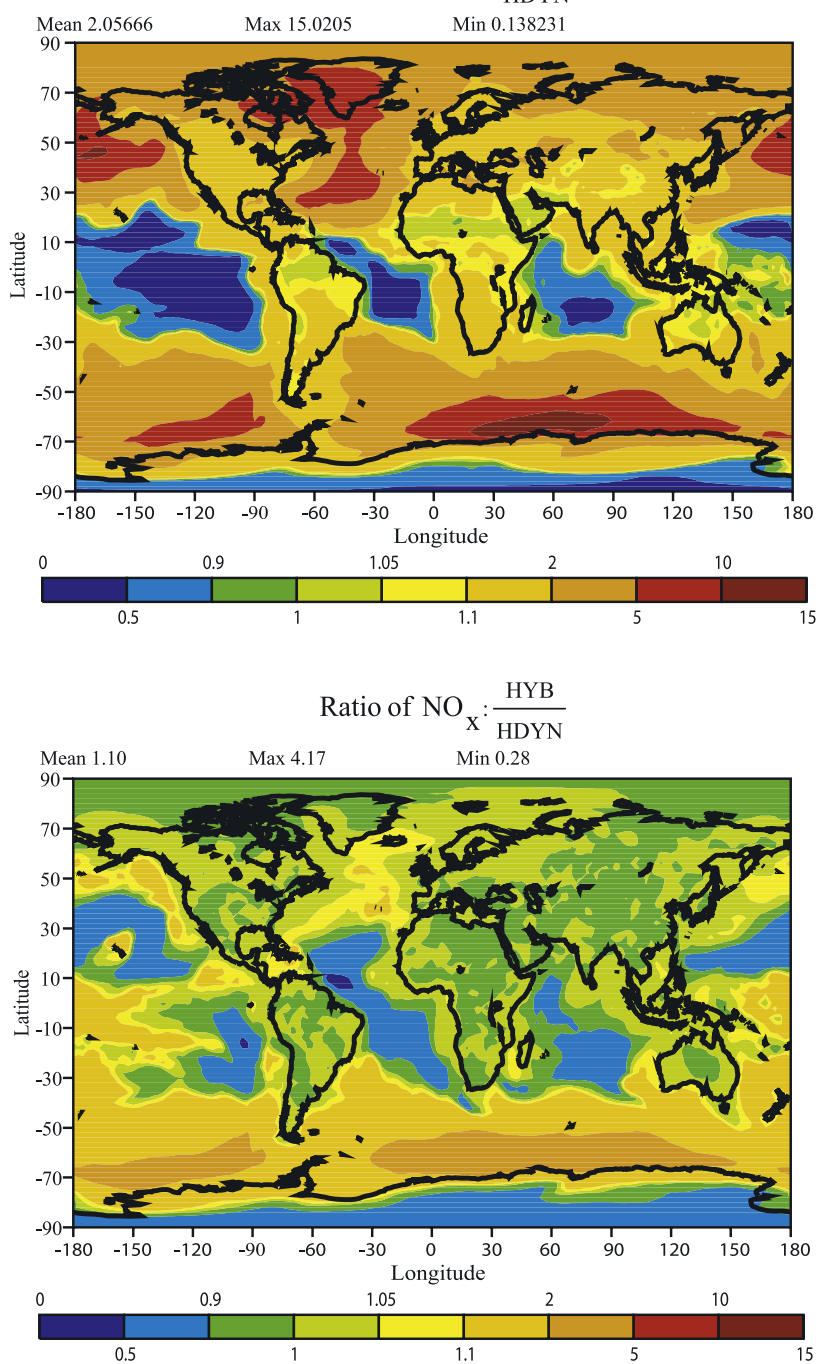

Figure 15. Geographic distribution of $\mathrm{HNO}_{3}(\mathrm{~g})$ and $\mathrm{NO}_{\mathrm{x}}$ concentrations (pptv) in the lowest three layers of the model, calculated by HDYN. Also shown are the ratios of $\mathrm{HNO}_{3}(\mathrm{~g})$ and $\mathrm{NO}_{\mathrm{x}}$ concentrations calculated by UPTAKE and HYB over those of HDYN. 

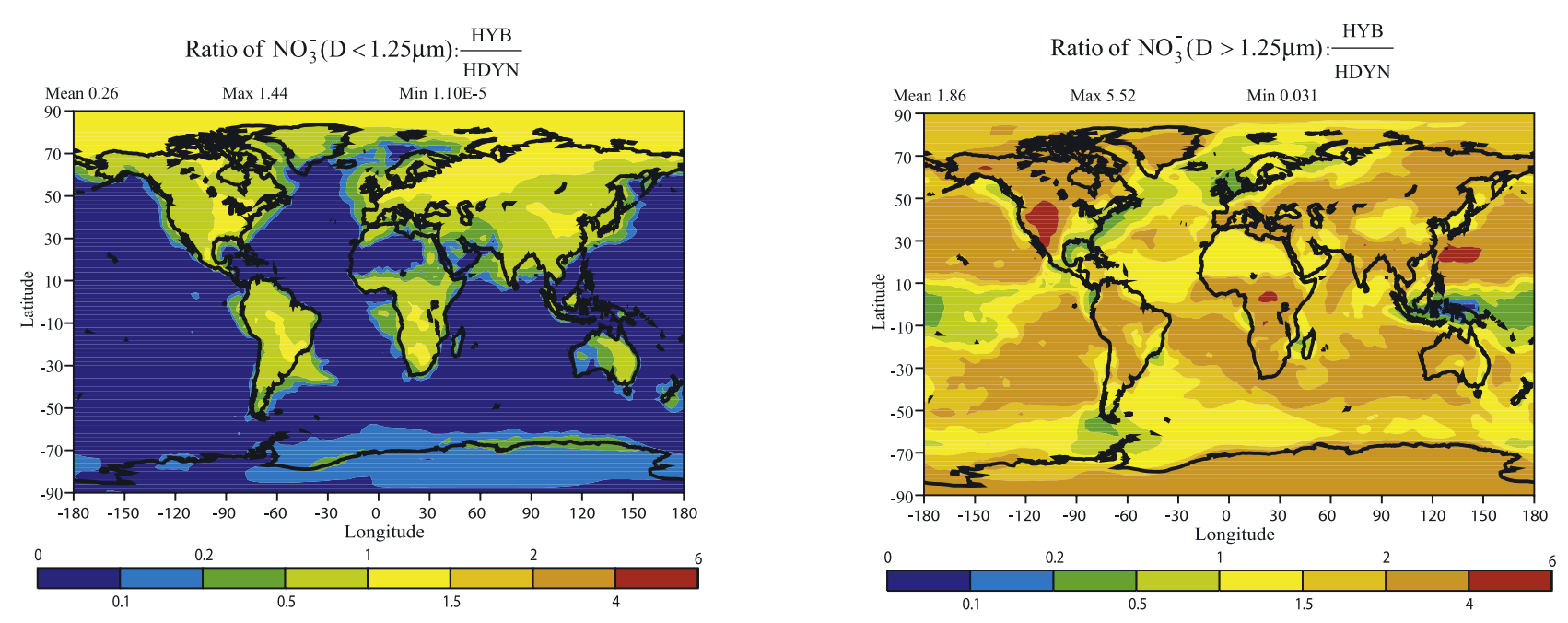

Figure 16. Ratios of $\mathrm{NO}_{3}^{-}$concentrations in $\mathrm{HYB}$ and $\mathrm{HDYN}$ in the lowest three layers of the model.

the NH. The surface $\mathrm{NO}_{\mathrm{x}}$ concentrations are thus overpredicted by UPTAKE by 2 to 5 times than that in HDYN over $\mathrm{NO}_{\mathrm{x}}$ source regions, whereas they are underestimated by HYB by less than $5 \%$. The ratio of $\mathrm{HNO}_{3}$ calculated by HYB and UPTAKE to that calculated by HDYN is larger than 1 over the oceans, since these models do not treat sea salt aerosols. Both UPTAKE and HYB predict higher $\mathrm{HNO}_{3}$ concentrations than HDYN over a very small area in central Africa where nitrate exists mainly in the aerosol phase. Because of the very low surface vapor pressure of $\mathrm{HNO}_{3}$ on dust in these regions, the uptake of nitrate is limited by the diffusion rate. Therefore $\mathrm{HNO}_{3}$ is removed more efficiently by HDYN, because it calculates a larger diffusion rate of $\mathrm{HNO}_{3}$ based on its accommodation coefficient (0.19) than that calculated in UPTAKE and HYB (which used an uptake coefficient of 0.1).

[56] As shown in Table 4, UPTAKE computes 70\% more fine-mode nitrate aerosol than HDYN with an even higher overestimation of coarse mode nitrate. A similar fine-mode nitrate aerosol burden is calculated by HYB $(0.075 \mathrm{Tg} \mathrm{N})$ compared to that of HDYN (0.079 Tg N). However, the nitrate aerosol burden in the coarse mode is 2 times larger in HYB $(0.18 \mathrm{Tg} \mathrm{N})$ than in HDYN $(0.086 \mathrm{Tg} \mathrm{N})$. Figure 16 shows the geographic distributions of the ratio of the fineand coarse-mode aerosol nitrate in HYB to HDYN in the lowest three layers of the model. Aerosol nitrate concentrations in the coarse mode are overestimated by HYB over most of the model domain by up to a factor of 6 . These overestimates are because HYB does not account for the interactive calculation of the $\mathrm{HNO}_{3}$ concentration on the aerosol surface during the mass transport. Thus, assuming a constant $\mathrm{HNO}_{3}$ uptake coefficient of 0.1 is generally too large. The overestimate by HYB is smaller over the major deserts because HYB does not allow further uptake of nitrate after nitrate on dust aerosol exceeds the amount of alkaline compounds in the dust. When the uptake coefficient (0.1) used by HYB is not sufficient, e.g., in a small region in central Africa, HYB still estimates higher nitrate concentrations than HDYN. This is because nitrate in the aerosol size range from 1.25 to $5.0 \mu \mathrm{m}$ diameter (bins 2 and 3) deposits more efficiently in HDYN (where the relative humidity growth of nitrate in dry deposition is assumed to be the same as that of sea salt because it has the largest mass on a global basis in these size bins) than in HYB (where the relative humidity growth is assumed to be the same as dust by the exclusion of sea salt aerosol).

[57] As in the calculations that used the thermodynamic equilibrium assumption, HYB underestimates the fine-mode nitrate concentrations by up to $50 \%$ over the remote continents and by much more over the deserts, compared to HDYN, because of the excessive formation of nitrate on coarse aerosols. HYB only assumes ammonium sulfate and ammonium nitrate aerosol in the fine mode, while HDYN assumes an ammonium sulfate, ammonium nitrate and dust aerosol mixture. Therefore some of the sulfate in HDYN may form solid compounds with dust at low temperatures and thereby impede the uptake of nitrate so that HYB may predict more fine-mode nitrate than does HDYN for these conditions. Over the oceans, less aerosol nitrate in both size modes is calculated by HYB because of the exclusion of sea salt aerosol.

\subsection{Comparison With Ground-Based Measurements}

[58] The calculated nitrate and ammonium aerosol concentrations using the HDYN, EQ, and HYB methods are compared with the available ground-based measurements in Figure 17. Results from the UPTAKE method are not shown here, since this method is usually used to account for the effects of aerosols on gas-phase chemistry and not applied to calculate aerosol concentrations. Sulfate and sea salt aerosol concentrations are also shown. Different treatments for nitrate and ammonium did not change the concentrations of primary aerosols such as sea salt at all, but slightly changed sulfate aerosol concentrations through the reaction of $\mathrm{SO}_{2}$ oxidation by $\mathrm{NO}_{3}$.

[59] For each of the three methods, there is much less scatter between the modeled predictions of nitrate and ammonium aerosol concentrations and the observations at the polluted continental sites in North America and Europe (Figure 17a) than that at the marine sites (Figure 17b). This is because the transport model does much better in predicting sulfate aerosol concentrations over the polluted con- 

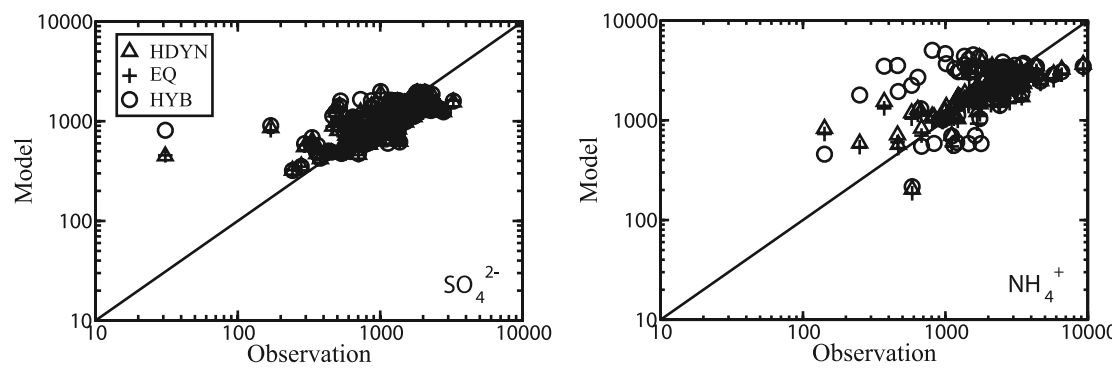

(a)
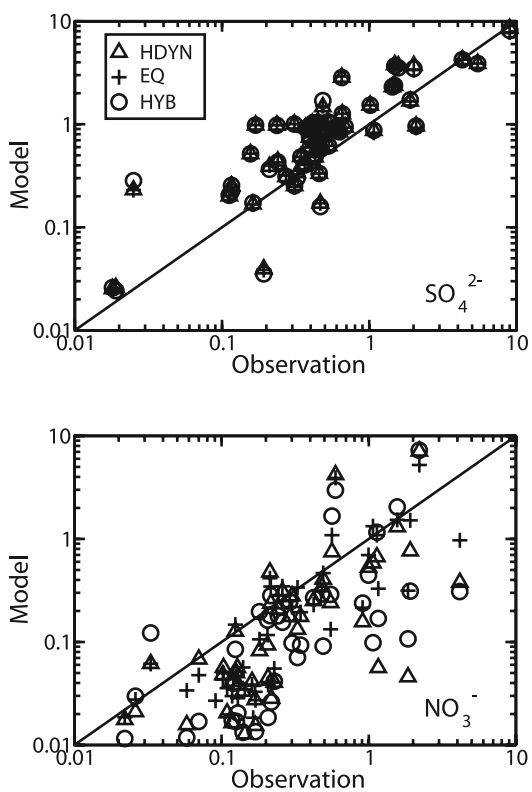

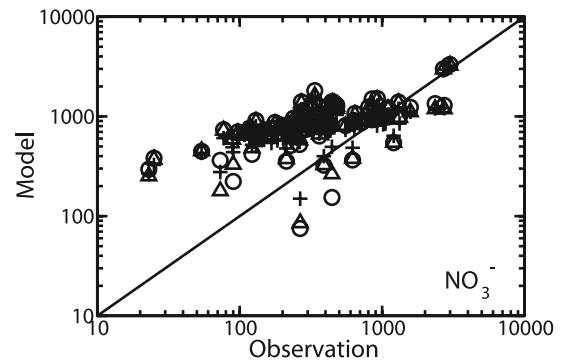

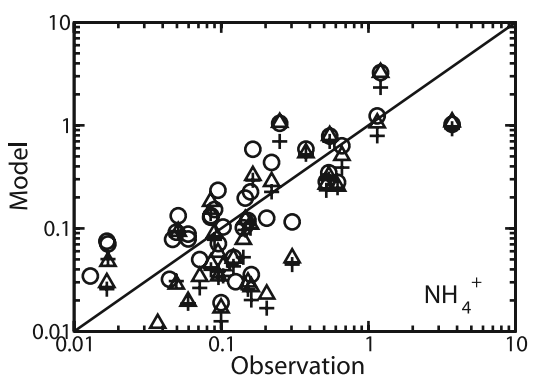

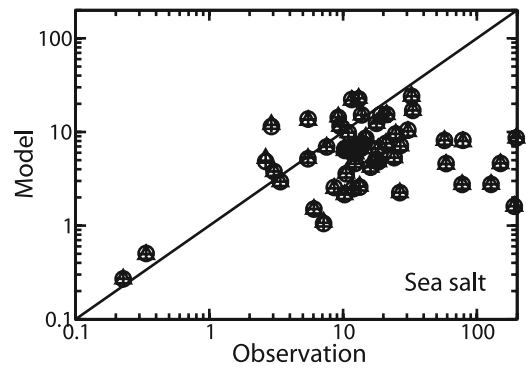

(b)

Figure 17. Comparison of the observed and modeled aerosol concentrations at (a) the polluted continental sites shown in Figure 11 (units are pptv) and (b) the marine sites shown in Figures 10a and $10 \mathrm{~b}$ (units are $\mu \mathrm{g} / \mathrm{m}^{3}$ ). Triangles, pluses, and circles represent the HDYN, EQ, and HYB calculations, respectively.

tinents than in predicting sulfate and sea salt aerosol concentrations over the ocean. A second possible reason is that the total predicted nitrate and ammonium (gas plus aerosol) available over the ocean is more sensitive to the precipitation removal rates in the global model [Liousse et al., 1996].

[60] For ammonium aerosol, the exclusion of sea salt aerosol by the HYB method results in overestimations at some continental sites, compared with the HDYN and EQ methods. Nitrate aerosol concentrations between the HDYN, EQ, and HYB methods do not differ significantly over the polluted continents since they are mainly determined by the predicted sulfate aerosol concentrations. The differences are generally less than their deviations from the observations. On the other hand, the predicted ammonium and nitrate aerosol concentrations calculated by the three methods are quite different at most of the marine sites, and their differences are frequently comparable to the departure from the observations. Although it is hard to conclude which of the three methods performs better using this metric, this comparison suggests that the choice of treatment for nitrate and ammonium is more important over the ocean than over the polluted continents.

\section{Conclusion and Discussion}

[61] We have implemented a hybrid dynamical approach in a three-dimensional aerosol and chemistry model (Umich/IMPACT) to study the global distribution of nitrate and ammonium aerosol concentrations. This method is more accurate than the equilibrium model calculation and other approximate treatments for nitrate and ammonium uptake by aerosols because it includes thermodynamic calculations of the aerosol composition and also takes account of the particle size, chemical composition, and ambient meteorological conditions in the calculation of the mass transfer rates for semivolatile gases. Sulfate, sea salt and mineral dust aerosol are considered in the global model. Aerosols are internally mixed in the 4 size bins to provide reactive surfaces for heterogeneous reactions that include the conversion from $\mathrm{N}_{2} \mathrm{O}_{5}$ to $\mathrm{HNO}_{3}$ and the hydrolysis of $\mathrm{HNO}_{3}$ and $\mathrm{NH}_{3}$. The calculated sulfate, 
ammonium, and nitrate aerosol concentrations show good agreement with the ground-based observations over the oceans and on the polluted continents.

[62] Results from the global model study show that $43 \%$ of the nitrate aerosol burden $(0.16 \mathrm{Tg} \mathrm{N})$ and $92 \%$ of ammonium aerosol burden $(0.29 \mathrm{Tg} \mathrm{N})$ exist in the fine aerosol mode that scatters most efficiently. $30 \%$ and $78 \%$ of the total nitrate and ammonia (gas plus aerosol) in the atmosphere is in the aerosol phase, respectively. In contrast, the fine-model aerosol burden in the sensitivity study that used the thermodynamic equilibrium assumption is only $0.059 \mathrm{Tg} \mathrm{N}$, and thus underestimates the burden by $25 \%$ because of the excessive nitrate formation on coarse aerosols. These underpredictions are especially important in the remote continents or over the oceans, where the availability of the total nitrate is limited. Similar results are also found for ammonium aerosol, but to a much smaller extent.

[63] This study suggests that the formation of nitrate aerosol from $\mathrm{HNO}_{3}$ needs to be considered in tropospheric ozone chemistry models in addition to the formation of $\mathrm{HNO}_{3}$ heterogeneous conversion from $\mathrm{N}_{2} \mathrm{O}_{5}$. The presence of nitrate aerosol could enhance the tropospheric ozone decrease due to the loss of $\mathrm{NO}_{\mathrm{x}}$ by a few percent on the basis of our global budget analysis with the potential for larger regional changes. Moreover, aerosol nitrate has a longer lifetime than nitric acid and is removed more efficiently by wet deposition. So these differences will affect the global distribution of atmospheric nitrogen deposition, which has been indicated to be important in the global carbon cycle in the biosphere.

[64] The calculated total nitrate aerosol burdens by HYB and UPTAKE are higher than those of HDYN by $+106 \%$ and $+47 \%$, respectively. While both the fine- and coarsemode nitrate aerosols are overestimated significantly by UPTAKE, HYB overpredicts nitrate on coarse aerosols but underpredicts nitrate on fine-mode aerosols. As a result of overestimating aerosol nitrate, HYB calculates lower surface $\mathrm{HNO}_{3}$ and $\mathrm{NO}_{\mathrm{x}}$ concentrations over continents by up to $90 \%$ and $5 \%$, respectively, compared to HDYN. On the other hand, underestimates in $\mathrm{HNO}_{3}$ and $\mathrm{NO}_{\mathrm{x}}$ due to the overpredicted nitrate aerosol by UPTAKE are offset by its exclusion of sulfate aerosol. Instead, it overpredicts the tropospheric $\mathrm{NO}_{\mathrm{x}}$ burden by $56 \%$ and the surface $\mathrm{NO}_{\mathrm{x}}$ concentrations by as much as a factor of 2 to 5 . On the basis of the global and annual budget of HDYN, $68 \%$ of the heterogeneous conversion of $\mathrm{N}_{2} \mathrm{O}_{5}$ to nitrate occurs on sulfate aerosol, while dust and sea salt aerosols contribute only $30 \%$ and $2 \%$, respectively.

[65] The comparison of different partitioning methods in the same model framework indicates that the large differences in $\mathrm{HNO}_{3}$ and $\mathrm{NO}_{\mathrm{x}}$ associated with the calculation of nitrate aerosol alone might be able to explain the large variation, from $5 \% \sim 16 \%$, in the previous estimates of the decrease of tropospheric ozone due to heterogeneous interactions with aerosols. Furthermore, the comparison of the calculated fine-mode nitrate aerosol implies that direct nitrate forcing estimates calculated with a thermodynamic equilibrium model or a simple hybrid approach (HYB) such as that used by Liao et al. [2003] will be underpredicted greatly or to a lesser extent, respectively, compared to that with the HDYN method [Feng et al., 2005].
[66] This study has demonstrated the importance of using the more accurate hybrid dynamical approach in the calculation of nitrate and ammonium aerosol in global aerosol and chemistry models, and has discussed the important implications for tropospheric ozone chemistry and for aerosol radiative forcing. Further research into the representation of emissions, deposition, and meteorological conditions are needed to reduce the uncertainties in the calculation of aerosol nitrate and ammonium concentrations.

[67] Acknowledgments. This work was funded by the DOE Atmospheric Chemistry Program and the NASA Atmospheric Chemistry, Modeling and Analysis Program.

\section{References}

Adams, P. J., J. H. Seinfeld, and D. M. Koch (1999), Global concentrations of tropospheric sulphate, nitrate and ammonium aerosol simulated in a general circulation model, J. Geophys. Res., 104, 13,791-13,823.

Adams, P. J., J. H. Seinfeld, D. Koch, L. Mickley, and D. Jacob (2001), General circulation model assessment of direct radiative forcing by the sulphate-nitrate-ammonium-water inorganic aerosol system, J. Geophys. Res., 106, 1097-1111.

Balkanski, Y. J., D. J. Jacob, G. M. Gardner, W. M. Graustein, and K. K. Turekian (1993), Transport and residence times of continental aerosols inferred from a global 3-dimensional simulation of ${ }^{210} \mathrm{~Pb}, J$. Geophys. Res., 98, 20,573-20,586.

Bauer, S. E., Y. Balkanski, M. Schulz, D. A. Hauglustaine, and F. Dentener (2004), Global modeling of heterogeneous chemistry on mineral aerosol surfaces: Influence on tropospheric ozone chemistry and comparison to observations, J. Geophys. Res., 109, D02304, doi:10.1029/ 2003JD003868.

Bouwman, A. F., D. S. Lee, W. A. H. Asman, F. J. Dentener, K. W. Van Der Hoek, and J. G. J. Olivier (1997), A global high-resolution emission inventory for ammonia, Global Biogeochem. Cycles, 11, 561-588.

Capaldo, K. P., C. Pilinis, and S. N. Pandis (2000), A computationally efficient hybrid approach for dynamic gas/aerosol transfer in air quality models, Atmos. Environ., 34, 3617-3627.

Chin, M., D. J. Jacob, G. M. Gardner, and P. A. Spiro (1996), A global three-dimensional model of tropospheric sulfate, J. Geophys. Res., 101, $18,667-18,690$.

Dassios, K. G., and S. N. Pandis (1999), The mass accommodation coefficient of ammonium nitrate aerosol, Atmos. Environ., 33, 2999-3003.

DeMore, W. B., S. P. Sander, D. M. Golden, R. F. Hampson, M. J. Kurylo, C. J. Howard, A. R. Ravishankara, C. E. Kolb, and M. J. Molina (1997), Chemical kinetics and photochemical data for use in stratospheric modeling, JPL Publ., JPL97-4, NASA Jet Propul. Lab., Pasadena, Calif.

Dentener, F. J., and P. J. Crutzen (1993), Reaction of $\mathrm{N}_{2} \mathrm{O}_{5}$ on tropospheric aerosols: Impact on the global distributions of $\mathrm{NO}_{\mathrm{x}}, \mathrm{O}_{3}$, and $\mathrm{OH}$, J. Geophys. Res., 98, 7149-7163.

Dentener, F. J., and P. Crutzen (1994), A three-dimensional model of the global ammonia cycle, J. Atmos. Chem., 19, 331-369.

Dentener, F. J., G. R. Carmichael, Y. Zhang, J. Lelieveld, and P. J. Crutzen (1996), Role of mineral aerosol as a reactive surface in the global troposphere, J. Geophys. Res., 101, 22,869-22,889.

Fan, X., K. Okada, N. Niimura, K. Kai, K. Arao, G. Shi, Y. Qin, and Y. Mitsuta (1996), Mineral particles collected in China and Japan during the same Asian dust-storm event, Atmos. Environ., 30, 347-351.

Feng, Y., J. E. Penner, S. Sillman, and X. Liu (2004), Effects of cloud overlap in photochemical models, J. Geophys. Res., 109, D04310, doi:10.1029/2003JD004040.

Feng, Y., J. E. Penner, and Y. Chen (2005), Global modeling of nitrate and ammonium: Implications on direct and indirect aerosol forcing, Eos Trans. AGU, 86(52), Fall Meet, Suppl., Abstract A51G-05.

Fuchs, N. A., and A. G. Sutugin (1971), High dispersed aerosols, in Topics in Current Aerosol Research (Part 2), edited by G. M. Hidy and J. R. Brock, pp. 1-200, Elsevier, New York.

Gerber, H. E. (1985), Relative-humidity parameterization of the Navy Aerosol Model (NAM), NRL Rep. 8956, Naval Res. Lab., Washington, D. C.

Gillette, D. A.. E. M. Patterson Jr., J. M. Prospero, and M. L. Jackson (1993), Soil aerosols, in Aerosol Effects on Climate, edited by S. G. Jennings, pp. 77-109, Univ. of Ariz., Tucson.

Ginoux, P., M. Chin, I. Tegen, J. M. Prospero, B. Holben, O. Dubovik, and S. J. Lin (2001), Sources and distributions of dust aerosols simulated with the GOCART model, J. Geophys. Res., 106, 20,255-20,273. 
Giorgi, F., and W. L. Chameides (1986), Rainout lifetimes of highly soluble aerosols and gases as inferred from simulations with a general circulation model, J. Geophys. Res., 91, 14,367-14,376.

Gong, S. L., L. A. Barrie, J. M. Prospero, D. L. Savoie, G. P. Ayers, J. P. Blanchet, and L. Spacek (1997), Modeling sea-salt aerosols in the atmosphere: 2. Atmospheric concentrations and fluxes, J. Geophys. Res., 102, 3819-3830.

Goodman, A. L., G. M. Underwood, and V. H. Grassian (2000), A laboratory study of the heterogeneous reaction of nitric acid on calcium carbonate particles, J. Geophys. Res., 105, 29,053-29,064.

Hjellbrekke, A.-G., and J. E. Hanssen (1998), Data report 1996, 1, Annual summaries, EMEP/CCC Rep. 1/98, 85 pp., Norw. Inst. for Air Res., Lillestrom.

Intergovernmental Panel on Climate Change (1994), Radiative Forcing of Climate Change and an Evaluation of the IPCC IS92 Emission Scenarios, edited by J. T. Houghton et al., Cambridge Univ. Press, New York.

Ito, A., J. E. Penner, and S. Sillman (2004), Impact of aromatics, terpenes, and additional organic nitrates on global tropospheric chemistry, Eos Trans. $A G U, 85(47)$, Fall Meet. Suppl., Abstract A52B-07.

Jacob, D. J. (2000), Heterogeneous chemistry and tropospheric ozone, Atmos. Environ., 34, 2131-2159.

Jacob, D. J., and S. C. Wofsy (1990), Budgets of reactive nitrogen, hydrocarbons, and ozone over the Amazon forest during the wet season, J. Geophys. Res., 95, 16,737-16,754.

Jacobson, M. Z. (1999), Studying the effects of calcium and magnesium on size-distributed nitrate and ammonium with EQUISOLV II, Atmos. Environ., 33, 3635-3649.

Jacobson, M. Z. (2001), Global direct radiative forcing due to multicomponent anthropogenic and natural aerosols, J. Geophys. Res., 106, $1551-$ 1568.

Jaenicke, R. (1988), Landolt-Bornstein zahlenwerte und funktionen aus naturwissenschaften und technik, in Meteorologie, B, Physikalishe und Chemische Eigenschaften der Luft, vol. 4, pp. 391-457, Springer, New York

John, W., S. M. Wall, J. L. Ondo, and W. Winklmayr (1989), Acidic-aerosol size distributions during SCAQS (Southern California Air Quality Study), final report, Rep. CA/DOH/AIHL/SP-51, Calif. Air Resour. Board, Sacramento.

Kraus, A. B., F. Rohrer, E. S. Grobler, and D. H. Ehhalt (1996), The global tropospheric distribution of $\mathrm{NO}_{\mathrm{x}}$ estimated by a three-dimensional chemical tracer model, J. Geophys. Res., 101, 18,587-18,604.

Kulmala, M., A. Laaksonen, P. Korhonen, T. Vesala, and T. Ahonen (1993), The effect of atmospheric nitric acid vapor on cloud condensation nucleus activation, J. Geophys. Res., 98, 22,949-22,958.

Kulmala, M., P. Korhonen, A. Laaksonen, and T. Vesala (1995), Changes in cloud properties due to $\mathrm{NO}_{\mathrm{x}}$ emissions, Geophys. Res. Lett., 22, 239242.

Kulmala, M., A. Toivonen, T. Mattila, and P. Korhonen (1998), Variations of cloud droplet concentrations and the optical properties of clouds due to changing hygroscopicity: A model study, J. Geophys. Res., 103, 16,18316,195 .

Lamarque, J.-F., et al. (2005), Assessing future nitrogen deposition and carbon cycle feedback using a multimodel approach: Analysis of nitrogen deposition, J. Geophys. Res., 110, D19303, doi:10.1029/2005JD005825.

Lelieveld, J., G. J. Roelofs, L. Ganzeveld, J. Feichter, and H. Rodhe (1997), Terrestrial sources and distribution of atmospheric sulphur, Philos. Trans. R. Soc., Ser. B., 352, 149-158.

Liao, H., P. J. Adams, S. H. Chung, J. H. Seinfeld, L. J. Mickley, and D. J. Jacob (2003), Interactions between tropospheric chemistry and aerosols in a unified general circulation model, J. Geophys. Res., 108(D1), 4001, doi:10.1029/2001JD001260.

Liao, H., J. H. Seinfeld, P. J. Adams, and L. J. Mickley (2004), Global radiative forcing of coupled tropospheric ozone and aerosols in a unified general circulation model, J. Geophys. Res., 109, D16207, doi:10.1029/ 2003JD004456

Lin, S.-J., and R. B. Rood (1996), Multidimensional flux-form semiLagrangian transport schemes, Mon. Weather Rev., 124, 2046-2070.

Liousse, C., J. E. Penner, C. Chuang, J. J. Walton, H. Eddleman, and H. Cachier (1996), A global three-dimensional model study of carbonaceous aerosols, J. Geophys. Res., 101, 19,411-19,432.

Liu, H., D. J. Jacob, I. Bey, and R. M. Yantosca (2001), Constraints from ${ }^{210} \mathrm{~Pb}$ and ${ }^{7} \mathrm{Be}$ on wet deposition and transport in a global threedimensional chemical tracer model driven by assimilated meteorological fields, J. Geophys. Res., 106, 12,109-12,128.

Liu, X., and J. E. Penner (2002), Effect of Mount Pinatubo $\mathrm{H}_{2} \mathrm{SO}_{4} / \mathrm{H}_{2} \mathrm{O}$ aerosol on ice nucleation in the upper troposphere using a global chemistry and transport model, J. Geophys. Res., 107(D12), 4141, doi:10.1029/2001JD000455.

Liu, X., J. E. Penner, and M. Herzog (2005), Global modeling of aerosol dynamics: Model description, evaluation, and interactions between sul- fate and nonsulfate aerosols, J. Geophys. Res., 110, D18206, doi:10.1029/ 2004JD005674.

Lurmann, F. W., A. S. Wexler, S. N. Pandis, S. Musarra, N. Kumar, and J. H. Seinfeld (1997), Modeling urban and regional aerosols, II, Application to California's south coast air basin, Atmos. Environ., $31,2695-2715$.

Mari, C., D. J. Jacob, and P. Bechtold (2000), Transport and scavenging of soluble gases in a deep convective cloud, J. Geophys. Res., 105, 22,25522,268.

McNaughton, D. J., and R. J. Vet (1996), Eulerian Model Evaluation Field Study (EMEFS): A summary of surface network measurements and data quality, Atmos. Environ., 30, 227-238.

Meng, Z., and J. H. Seinfeld (1996), Time scales to achieve atmospheric gas-aerosol equilibrium for volatile species, Atmos. Environ., 30, 28892900.

Metzger, S., F. Dentener, M. Krol, A. Jeuken, and J. Lelieveld (2002), Gas/ aerosol partitioning: 2. Global modeling results, J. Geophys. Res., 107(D16), 4313, doi:10.1029/2001JD001103.

Monahan, E. C., D. E. Spiel, and K. L. Davidson (1986), A model of marine aerosol generation via whitecaps and wave disruption, in Oceanic Whitecaps and Their Role in Air-Sea Exchange, edited by E. C. Monahan, and G. MacNiocaill, pp. 167-174, Springer, New York.

Niimura, N., K. Okada, X. Fan, K. Kai, K. Arao, G. Y. Shi, and S. Takahashi (1998), Formation of Asian dust-storm particles mixed internally with sea salt in the atmosphere, J. Meteorol. Soc. Jpn., 76, 275-288.

Okada, K., et al. (1990), X-ray spectrometry of individual Asian dust-storm particles over the Japanese Islands and the North Pacific Ocean, Atmos. Environ., Part A, 24, 1369-1378.

Pakkanen, T. A., et al. (1999), Nordic intercomparison for measurement of major atmospheric nitrogen species, J. Aerosol Sci., 30, 247-263.

Pandis, S. N., A. S. Wexler, and J. H. Seinfeld (1993), Secondary organic aerosol formation and transport, II, Predicting the ambient secondary organic aerosol size distribution, Atmos. Environ., Part A, 27, 2403 2416.

Penner, J. E., C. A. Atherton, and T. E. Graedel (1994), Global emissions and models of photochemically active compounds, in Global Atmospheric-Biospheric Chemistry, edited by R. Prinn, pp. 223-248, Springer, New York.

Penner, J. E., C. C. Chuang, and K. Grant (1998), Climate forcing by carbonaceous and sulphate aerosols, Clim. Dyn., 14, 839-851.

Riemer, N., H. Vogel, B. Vogel, B. Schell, I. Ackermann, C. Kessler, and $\mathrm{H}$. Hass (2003), Impact of the heterogeneous hydrolysis of $\mathrm{N}_{2} \mathrm{O}_{5}$ on chemistry and nitrate aerosol formation in the lower troposphere under photosmog conditions, J. Geophys. Res., 108(D4), 4144 doi:10.1029/2002JD002436.

Rodriguez, M. A., and D. Dabdub (2004), IMAGES-SCAPE2: A modeling study of size- and chemically resolved aerosol thermodynamics in a global chemical transport model, J. Geophys. Res., 109, D02203, doi:10.1029/2003JD003639.

Rotman, D. A., et al. (2004), IMPACT, the LLNL 3-D global atmospheric chemical transport model for the combined troposphere and stratosphere: Model description and analysis of ozone and other trace gases, J. Geophys. Res., 109, D04303, doi:10.1029/2002JD003155.

Saxena, P., and L. M. Hildemann (1996), Water soluble organics in atmospheric particles: A critical review of the literature and application of thermodynamics to identify candidate compounds, J. Atmos. Chem., 24, 57-109.

Schlesinger, W. H., and A. E. Hartley (1992), A global budget for atmospheric $\mathrm{NH}_{3}$, Biogeochemistry, 15, 191-211.

Schultz, M. G., et al. (1999), On the origin of tropospheric ozone and $\mathrm{NO}_{\mathrm{x}}$ over the tropical South Pacific, J. Geophys. Res., 104, 5829-5844.

Schwartz, S. E. (1986), Mass transport considerations pertinent to aqueousphase reactions of gases in liquid-water clouds, in Chemistry of Multiphase Atmospheric Systems, edited by W. Jaeschke, pp. 415-471, Springer, New York.

Seinfeld, J. H., and S. N. Pandis (1998), Atmospheric Chemistry and Physics: From Air Pollution to Climate Change, John Wiley, Hoboken, N. J. Singh, H., et al. (2000), Distribution and fate of selected oxygenated organic species in the troposphere and lower stratosphere over the Atlantic, J. Geophys. Res., 105, 3795-3806.

Singh, H. B., et al. (1998), Latitudinal distribution of reactive nitrogen in the free troposphere over the Pacific Ocean in late winter/early spring, J. Geophys. Res., 103, 28,237-28,247.

Tang, I. N., and H. R. Munkelwitz (1994), Water activities, densities, and refractive indices of aqueous sulfate and sodium nitrate droplets of atmospheric importance, J. Geophys. Res., 99, 18,801-18,808.

Takemura, T., H. Okamoto, Y. Maruyama, A. Numaguti, A. Higurashi, and T. Nakajima (2000), Global three-dimensional simulation of aerosol optical thickness distribution of various origins, J. Geophys. Res., 105, $17,853-17,873$ 
Tegen, I., S. P. Harrison, K. Kohfeld, I. C. Prentice, M. Coe, and M. Heimann (2002), Impact of vegetation and preferential source areas on global dust aerosol: Results from a model study, J. Geophys. Res., 107(D21), 4576, doi:10.1029/2001JD000963.

ten Brink, H. M., J. P. Veefkind, A. Waijers-Ijpelaan, and J. C. van der Hage (1996), Aerosol light-scattering in the Netherlands, Atmos. Environ., 30 , $4251-4261$.

Tie, X., et al. (2003), Effect of sulfate aerosol on tropospheric $\mathrm{NO}_{\mathrm{x}}$ and ozone budgets: Model simulations and TOPSE evidence, J. Geophys. Res., 108(D4), 8364, doi:10.1029/2001JD001508.

Van Doren, J. M., L. R. Watson, P. Davidovits, D. R. Worsnop, M. S. Zahniser, and C. E. Kolb (1990), Temperature dependence of the uptake coefficient of $\mathrm{HNO}_{3}, \mathrm{HCl}$ and $\mathrm{N}_{2} \mathrm{O}_{5}$ on water droplets, J. Phys. Chem., 94, 3265-3269.

Van Doren, J. M., L. R. Watson, P. Davidovits, D. R. Worsnop, M. S Zahniser, and C. E. Kolb (1991), Uptake of $\mathrm{N}_{2} \mathrm{O}_{5}$ and $\mathrm{HNO}_{3}$ on aqueous sulfuric acid droplets as a function of sulfuric acid concentration: Coefficients and branching ratio, J. Phys. Chem., 95, 1684-1689.

Van Dorland, R., F. J. Dentener, and J. Lelieveld (1997), Radiative forcing due to tropospheric ozone and sulphate aerosols, J. Geophys. Res., 102, $28,079-28,100$

Walcek, C. J., R. A. Brost, and J. S. Chang (1986), $\mathrm{SO}_{2}$, sulfate and $\mathrm{HNO}_{3}$ deposition velocities computed using regional land use and meteorological data, Atmos. Environ., 20, 949-964.

Warneck, P. (1988), Chemistry of the Natural Atmosphere, 757 pp., Elsevier, New York.
Wesely, M. L. (1989), Parameterization of surface resistances to gaseous dry deposition in regional-scale numerical models, Atmos. Environ., 23, $1293-1304$

Wexler, A. S., and J. H. Seinfeld (1990), The distribution of ammonium salts among a size and composition dispersed aerosol, Atmos. Environ., Part A, 24, 1231-1246.

Yamato, Y., and H. Tanaka (1994), Aircraft observations of aerosols in the free marine troposphere over the North Pacific Ocean: Particle chemistry in relation to air mass origin, J. Geophys. Res., 99, 5353-5377.

Zhang, D., Y. Iwasaka, G. Shi, J. Zang, A. Matsuki, and D. Trochkine (2003), Mixture state and size of Asian dust particles collected at southwestern Japan in spring 2000, J. Geophys. Res., 108(D24), 4760, doi:10.1029/2003JD003869.

Zhang, L., S. L. Gong, J. Padro, and L. Barrie (2001), A size-segregated particle dry deposition scheme for an atmospheric aerosol module, Atmos. Environ., 35(3), 549-560.

Zhou, M., K. Okada, F. Qian, P.-M. Wu, L. Su, B. E. Casareto, and T. Shimohara (1996), Characteristics of dust-storm particles and their long-range transport from China to Japan-Case studies in April 1993, Atmos. Res., 40, 19-31.

Y. Feng and J. E. Penner, Department of Atmospheric, Oceanic and Space Sciences, University of Michigan, Ann Arbor, MI 48109-1349, USA. (yafeng@ucsd.edu) 